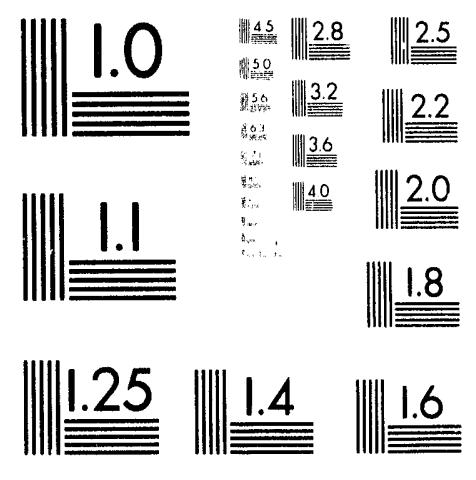



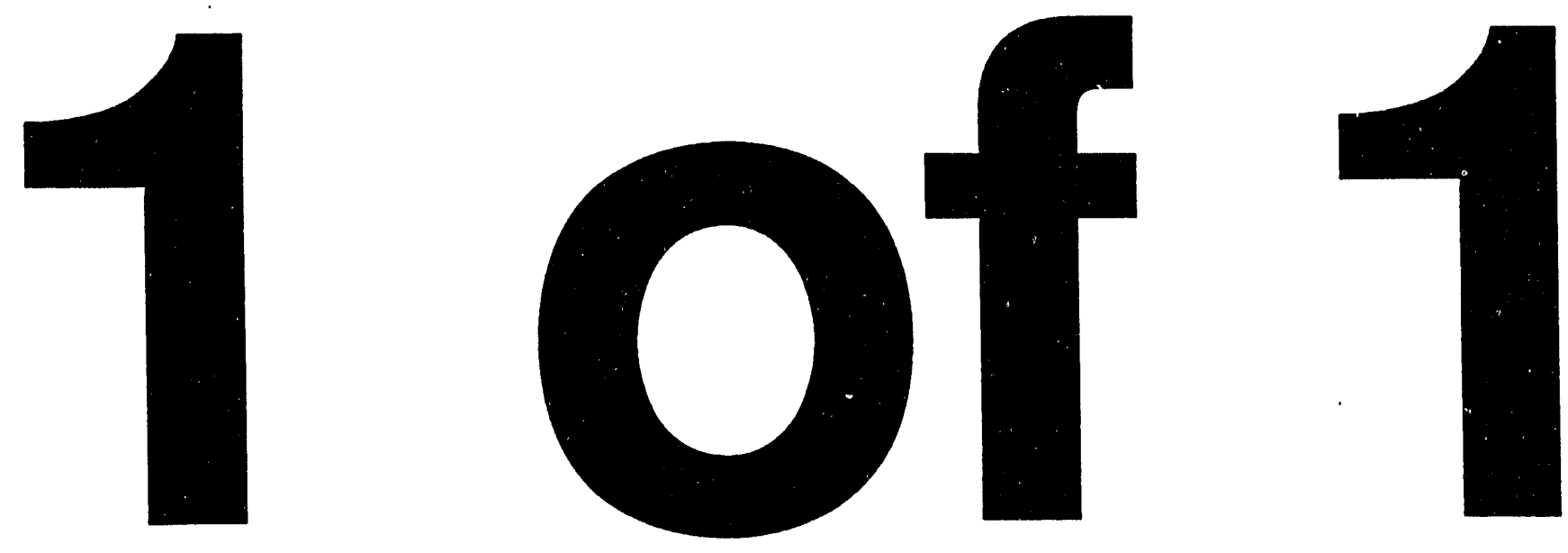


\title{
The Price of Electricity from Private Power Producers
}

\author{
Edward Kahn, Adele Milne and Suzie Kito \\ Energy and Environment Division \\ Lawrence Berkeley Laboratory \\ University of California \\ Berkeley, CA 94720
}

October 1993

The work described in this report was funded by the Assistant Secretary of Energy Efficiency and Renewable Energy, Office of Utility Technologies, Office of Energy Management Division and the Assistant Secretary for Fossil Energy of the U.S. Department of Energy under Contract No. DE-AC03-76SF00098. 


\section{Table of Contents}

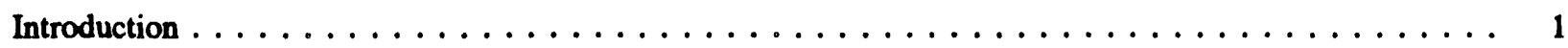

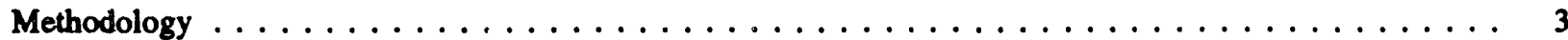

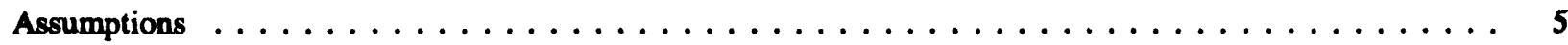

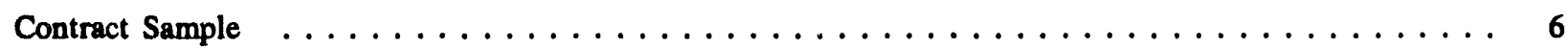

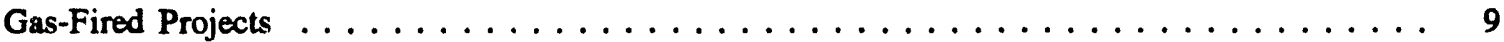

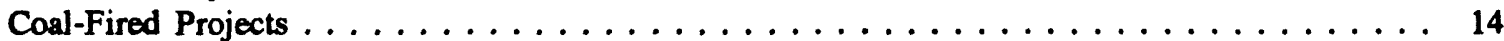

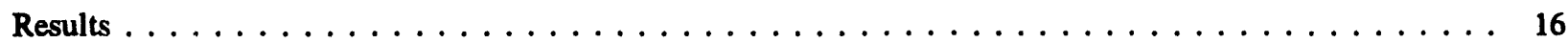

Towards an Explanatory Theory of Prices $\ldots \ldots \ldots \ldots \ldots \ldots \ldots \ldots \ldots \ldots \ldots$

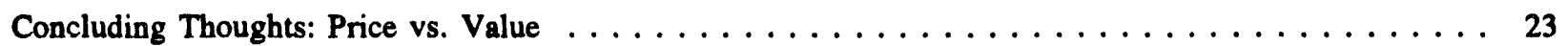

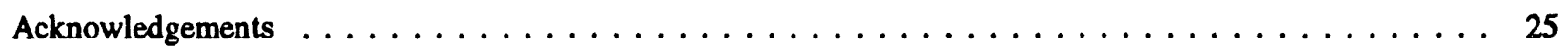

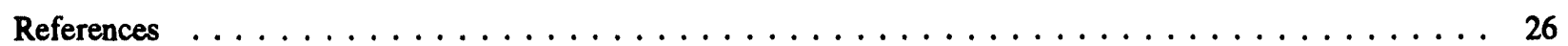

Appendix A

Price Calculation for Individual Projects $\ldots \ldots \ldots \ldots \ldots \ldots \ldots \ldots \ldots \ldots \ldots \ldots \ldots$ 


\section{List of Tables}

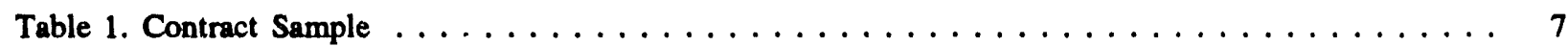

Table 2. Contract Pricing Provisions: Gas-Fired Projects $\ldots \ldots \ldots \ldots \ldots \ldots \ldots \ldots \ldots \ldots \ldots$

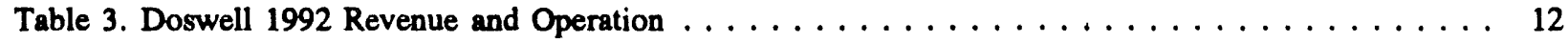

Table 4. Data Sorted by Price at $85 \%$ Capacity Factor $\ldots \ldots \ldots \ldots \ldots \ldots \ldots \ldots$ 


\section{List of Figures}

Figure 1. Contract Prices at Various Capacity Factors (with high gas price forecan) $\ldots \ldots \ldots \ldots \ldots$

Figure 2. Contract Prices at Various Capacity Factors (with low gas price forecaat) $\ldots \ldots \ldots \ldots \ldots \ldots$ 


\title{
The Price of Electricity from Private Power Producers
}

\author{
Edward Kahn, Adele Milne and Suzie Kito \\ Energy and Environment Division \\ Lawrence Berkeley Laboratory
}

October 1993

\begin{abstract}
The long-term wholesale electricity market is becoming increasingly competitive. Bidding for power contracts has become a dominant form of competition in this sector. The prices which emerge from this process have not been documented and compared in a systematic framework. This paper introduces a method to make such comparisons and illustrates it on a small sample of projects. The results show a wide range of prices for what is essentially the same technology, gas-fired combined cycle generation. The price range seems greater than what could be explained by transmission cost differences between high and low cost regions. For the smaller sample of coal-fired projects, price variation is substantially less. Further data collection and analysis should be able to help isolate more clearly what market or cost factors are responsible for the observed variation.
\end{abstract}

\section{Introduction}

\section{Background}

The introduction of competition into long-term wholesale electricity markets has important implications for the regulatory process. In addition to auditing the production and distribution costs of vertically integrated firms, regulators must now also pay attention to the prices paid to wholesale electricity suppliers. As the balance between generation from rate based resources and competitively bid resources shifts, more and more regulatory attention will shift to assessing the reasonableness of market price formation. Even before the passage of the Energy Policy Act (EPAct) of 1992, competitive bidding for private power projects was an important source of incremental electricity supply. Now that entry restrictions have been loosened by EPAct, private power production should expand further.

A market based process, however, does not necessarily mean that the markets in question are actually functioning as expected. Developing markets in industries that have long traditions of 
regulation can be a slow and uneven process. The role for regulation in the transition toward freer markets is to assess performance, and attempt to identify problems that may appear from such assessments. This activity has already begun, in a somewhat limited fashion, at the Federal Energy Regulatory Commission (FERC). Even before EPAct, FERC had decided to allow "market-based" pricing of private wholesale electric power projects. Defining a standard for a "market based" price led FERC to introduce a comparative price test, or benchmark, (TECO, 1990) and apply it in one case (OSP, 1992). For this kind of price regulation (as opposed to cost of service regulation) to be successful, it is necessary to develop methods and data collection procedures. Such methods could be expected to apply at the level of state regulation as well as federal regulation.

Price behavior in the private power market also has important implications for integrated resource planning. These prices will increasingly take on the role of a value standard for utility investments and DSM programs. Both planners and regulators need to have some measure of value based on alternative opportunities. Administrative estimates of avoided cost have played the role of a value standard in planning. As market price formation becomes better developed and more familiar, it is reasonable to expect that estimated avoided cost will be gradually replaced by a market price standard (expressed in a form suited to particular comparisons).

\section{Scope of This Study}

The purpose of this analysis is to compare systematically the prices of a small sample of independently owned and operated power projects that have been recently built, or are planned to operate in the near future. There is currently no generally accepted standardized form in which the long-term prices paid to electricity generators other than franchiseci utilities are expressed. Unlike FERC Form 1, which standardizes the accounting for regulated investorowned utilities, information about price derives primarily from the contracts signed between the purchaser of the electric output (the utility) and the company responsible for building and operating the plant (the Independent Power Producer). The contracts are available from the Public Utilities Commissions in the various states (with some exceptions). Some additional information is available from either the utilities or the Independent Power Producers associated with individual projects.

This study is a pilot project; an initial attempt to identify the range of variation in price formulas and to produce a consistent and standard procedure. We focus on eight projects all using a similar technology, natural gas-fired combustion turbines either in co-generation applications, combined cycle configuration or both. For comparison purposes, we also include three coal fired projects.

Power purchase contracts are complex documents containing numerous terms and conditions in addition to pricing formulas. Previous work has examined the range of variation in terms and conditions that privately built and operated projects offer (Kahn, 1991; NIEP, 1992). It is not a simple matter to compare the value of the different contract clauses. First, one must be able 
to calculate the contract prices in a consistent manner. Once a price is calculated, then one can attempt to estimate how much value ratepayers are getting for this price. Particular contract features may justify paying a higher electricity price. This report covers only the initial part of the question, namely how much is being paid by utilities under various contract pricing provisions.

This paper is structured in the following fashion. Section 2 outlines the methodological approach we take to characterizing price. Section 3 lists the common assumptions used in the analysis. The contract sample is characterized in Section 4. Results are summarized in Section 5. Section 6 outlines a variety of reasons that might account for price variation within a given technology. Finally, Section 7 discusses how results from this kind of analysis might be used.

\section{Methodology}

\section{Appropriate Units}

In this study, we compute the levelized cost of electricity as a function of the capacity factor. This results in each project being represented by a price curve. This representation was first used as a method to characterize price by Virginia Power (Ellis, 1989). The reason for adopting this approach is that the projects we examine are all contractually obligated to provide the purchasers with "dispatchability" privileges. This means that output from the projects can be varied (frequently within certain contractual limits) as the value of power fluctuates. Dispatchability requirements are becoming a threshold of acceptability to utility purchasers, and can be expected to continue as a feature of the private power market (Kahn, Marnay and Berman, 1992a).

Prices for electricity are computed for various capacity factors (e.g., 45\% - 95\%). Although some of the contracts allow for operation of the plant at less than full load, annual $\mathrm{kWh}$ output has been estimated as (capacity factor) $\times(8760) \times$ (rated plant capacity). Although this approximation ignores certain details, it provides a convenient form of standardization. Different summer and winter capacities have been accounted for by using an annual average. The exceptions are the Brooklyn Navy Yard contracts where we used the lower summer capacities for calculating the capacity payments, but increased the annual $\mathrm{kWh}$ by $12 \%$ to account for the higher winter capacities and additional electrical generation (see Section 4).

The contract lengths vary from 20 years to approximately 33 years. Prices have been levelized over the duration of the contract and no attempt has been made to adjust for the different contract lengths (see Section 5 for a discussion of the "end effects" issues). We have ignored those instances where contracts allow for optional contract extension under negotiated terms.

Although all contracts specify monthly payments, we have used annual payments for the calculations in this report. The convention adopted was to use the payment in the first month of operation multiplied by 12 for the first annual payment. This amount was assumed to be paid at the end of the 12 month period. Indexed price components were increased annually 
(contracts stipulate monthly or quarterly indexing, although they occasionally require annual indexing.) The error introduced by this convention (i.e., escalating costs annually) is consistent throughout, so that comparisons among contracts remain unaffected. Actual difference from "real life" cost depends on the discount rate, and the treatment of capital in the first 12 month contract period. For a $10 \%$ discount rate, the difference may be $5 \%$, or the difference between mid-year dollars and beginning of year dollars.

All payment streams have been discounted to the start of commercial operation. To compare projects with different start dates, prices have been inflated/deflated to mid-1992. Unless otherwise specified, prices are quoted in mid-1992 dollars.

\section{Information Sources}

It is important to understand the basic outlines of private power project development to appreciate when information about price is generated. Broadly speaking there are four sequential steps that precede the commercial operation of a private power project. These are (1) power purchase contract with the utility, (2) environmental permitting, (3) financing, and (4) construction. Of these four steps, only the first produces comprehensive and generally public information about price. The private producer faces large uncertainties about exactly what environmental restrictions will be imposed, and under what precise terms he will be able to finance construction and operation. These steps are sequential. Contracts must precede permits, and permits, or at least the strong indication of permits, must precede financing. Further, permit conditions, while public knowledge in principle, are not easily obtained. Financing terms, unless they involve publicly sold securities, are strictly private information. In the case of public securities, the information base is considerable (Kahn et al., 1992b), and we make some use of it in particular situations.

Because uncertainties must be resolved in the post-contract stages of development, project characteristics (including those that affect price) may change. In principle, those changes that influence price will be formalized in amendments to the power purchase contract. This is not always the case. Sometimes disputes may arise between the utility and the private producer over contract interpretation. There is an old saying among lawyers and economists that it is the fate of every long-term contract to end up in court. Such litigation is private, and parties to it do not comment outside of such proceedings.

A further information problem involves interface with the natural gas pipeline regulatory system. Contracts for gas-fired power projects incorporate reference to specific pipeline arrangements, sometimes even particular tariffs, in the contract language. The prices associated with pipeline service are subject to change. In some cases, the project bears the risk of such changes, in others, it is passed through to the utility and its customers. In the latter case, it is important to check for post-contract changes in developing an estimate of price. 
In this study, we rely primarily on the power purchase contract to estimate price. In all cases we have consulted with either the buyer or the seller to verify our interpretation of price. In some cases this results in significant changes from the contract. Of the eleven projects studied here, only three (Dartmouth, Doswell and Pedricktown) are in commercial operation.

\section{Assumptions}

We made a number of general assumptions applicable to all contracts. Contract specific assumptions are discussel in Section 4. The general assumptions include the following:

- A discount rate of $9.8 \%$, which was used for the levelized price calculations.

- An inflation rate of $4.1 \%$ per annum, which was used whenever price components were to escalate with the Gross National Product Implicit Price Deflator or Consumer Price Index.

- A "gas spot price index" escalator of $5.1 \%$ per annum (inflation plus $1 \%$ ), which was used whenever a gas cost was tied to an index which depended on a gas commodity price or combination of gas commodity prices. A sensitivity calculation is performed at a $7.1 \%$ annual escalation rate (inflation plus $3 \%$ ). ${ }^{1}$ We believe that it is appropriate under current gas market conditions to assume that there is only one spot market price (Lyon and Hackett, 1993; De Vany and Walls, 1992).

- A "gas transportation index" of $4.1 \%$ per annum, assuming that gas transportation costs (both fixed and variable) rise roughly with inflation. We used this assumption for both Canadian and U.S. pipeline transportation costs. It would be possible to alter this assumption to model contractually specified gas transportation demand costs, but the gas supply contracts are unavailable and the actual gas transportation costs are unknown. (Contracts for firm gas transportation will have higher gas transport capacity demand charges than non-firm supply agreements.)

- A "gas combined index" of $4.8 \%$ per annum, which was used whenever the contracts bundled both gas commodity and transportation costs. This figure weights the gas spot price index by $2 / 3$ and the gas transportation index by $1 / 3$, which approximates the relative importance of the gas commodity costs as compared to transportation costs. Using the same weighting, the combined index for the high gas price case is $6.1 \%$.

\footnotetext{
' In general, we ignored those situations where contracts allowed for gas prices to be adjusted when or if contract gas prices deviated substantially from actual gas prices ("re-opener" clauses). We also treated Canadian gas prices in the same manner as U.S. gas prices.
} 
- Gas operation of $100 \%$ for projects which can operate on gas or oil, which is probably a good approximation for those plants where oil is only an emergency backup fuel.

- Operation of all projects at the design capacity and expected availability so that the penalty and bonus provisions related to availability and capacity do not apply. In addition, we assumed that limits for start-ups and shut-downs were not exceeded so that additional costs would not be incurred.

- For projects that had begun operation, we used the actual date of commercial operation. For projects which had not begun operation, we used the start date specified in the contract. Where a range of possible start dates was given, we used the later start date.

\section{Contract Sample}

Eleven contracts are evaluated in this report. Three are based on coal, and eight on natural gas as the primary fuel. Details are given in Table 1. Length of contract refers to the time during which electricity is being sold to the Buyer. The Seller is identified by corporate name as listed in one of the standard private power industry surveys (Independent Power Report, 1992). The sample size at present is small, but illustrates a range of pricing methods and a range of project sizes (from $40 \mathrm{MW}$ to $600 \mathrm{MW}$ ). It is hoped that the method used to compare these projects can be used with a larger sample of projects in order to track trends in the industry.

The prices in the contracts are generally composed of fixed costs (paid regardiless of how often the plant is run) and variable costs (incurred only per output $\mathrm{kWh}$ from the plant). In some contracts there is a minimum number of operation hours stipulated. In these cases, costs which are apparently variable (per $\mathrm{kWh}$ ), are in fact partly fixed. The names for the payments, and the extent to which payments are disaggregated varies considerably. It is the lack of standardized pricing terminology which sometimes requires interpretation. Details on the individual contract payment provisions are discussed below.

Of the eight gas-fired projects, there is a wide range of pricing formulas. Details on the different structures are summarized in Table 2 (coal projects exhibit a much simpler structure and are not included in this table). One important reason for the variation associated with gas is the structural change that is occurring in the natural gas industry, particularly the changes in pipeline regulation. The basic trend is away from the pipeline sale of a "bundled" product of both commodity gas and transportation services. As a result of changes in markets and regulation, gas is increasingly being purchased directly by large end-users, who contract separately for transportation services. This trend, which began in the mid-1980s with FERC Orders 436 and 500, culminated in 1992 with Order 636, which codified the transition to a largely unbundled form of pipeline service (EIA, 1989; EIA, 1993; FERC, 1992). The contracts in our sample span this time period, and reflect the unbundling trend with varying degrees of explicitness. Further 


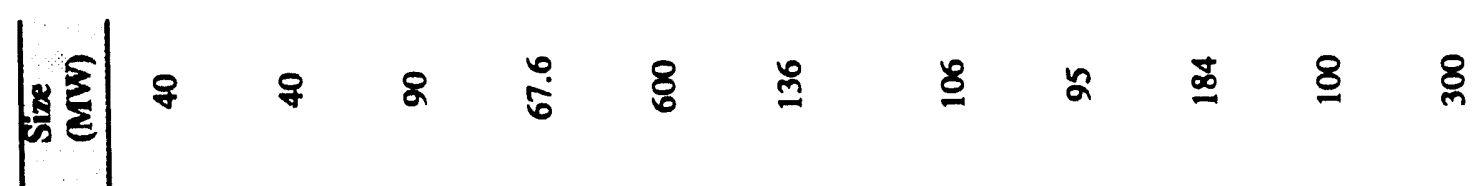

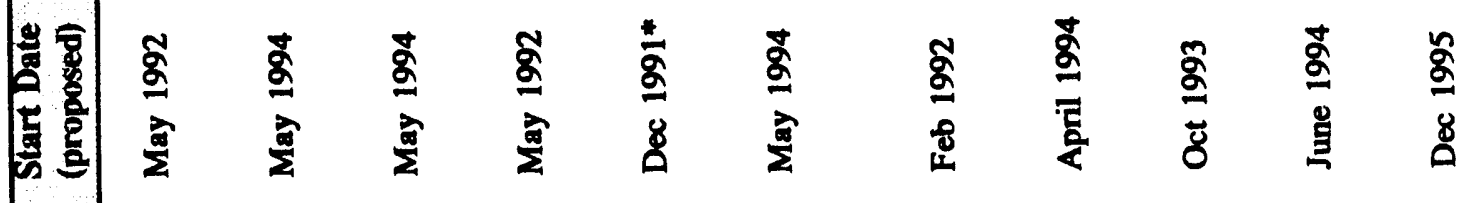
क

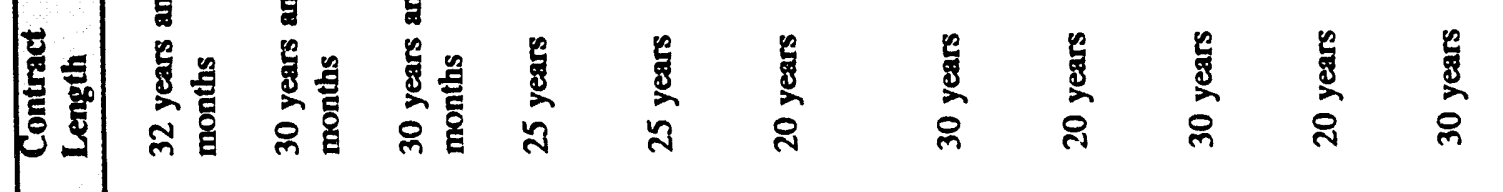

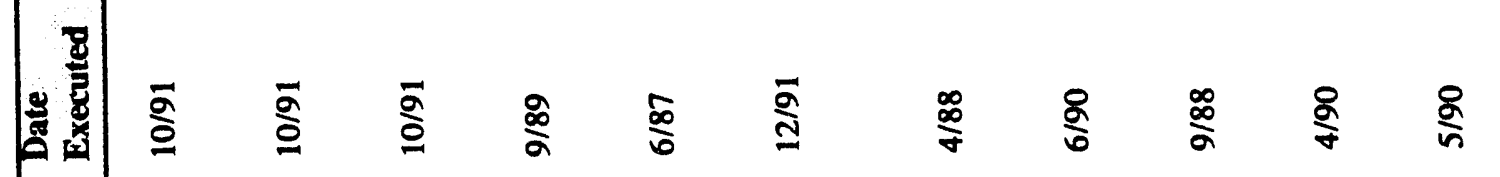

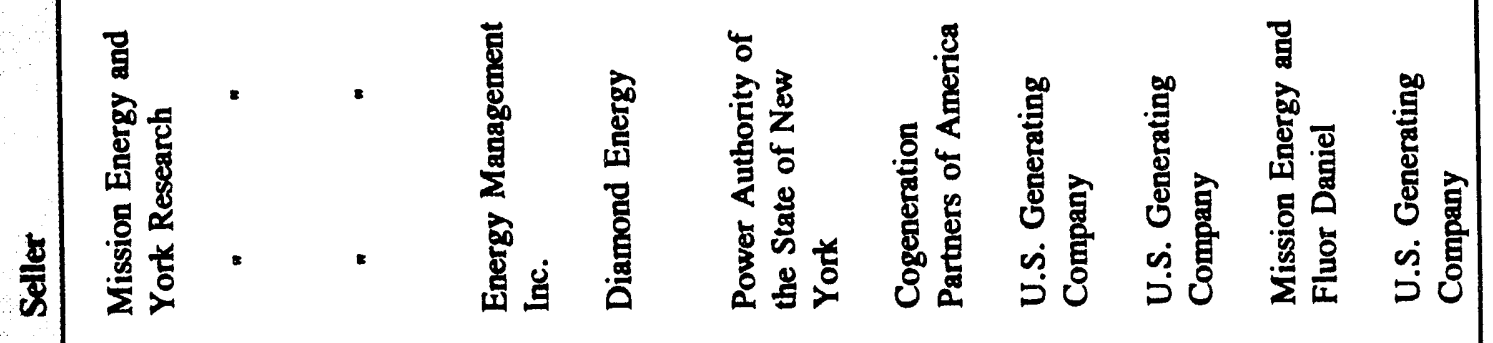

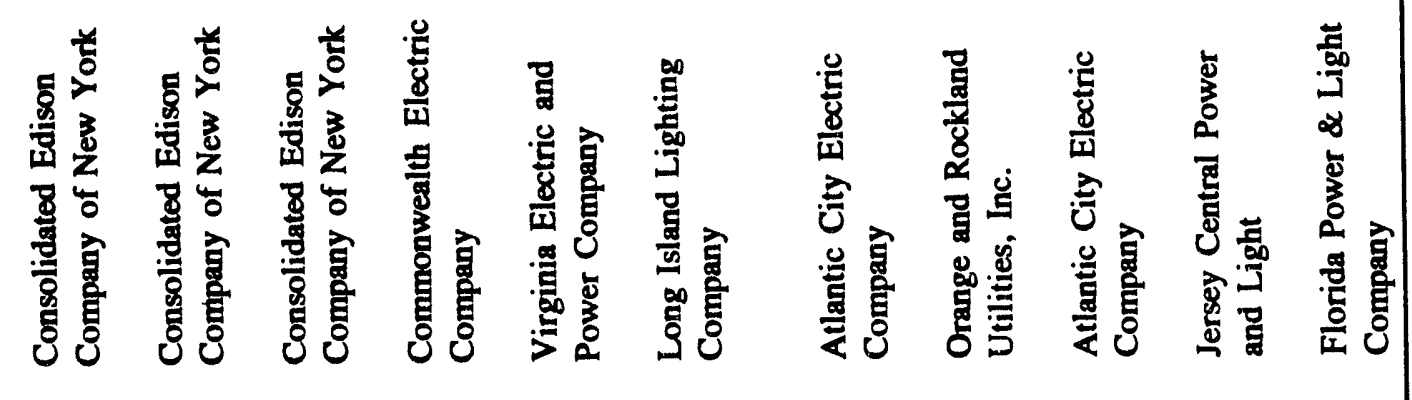

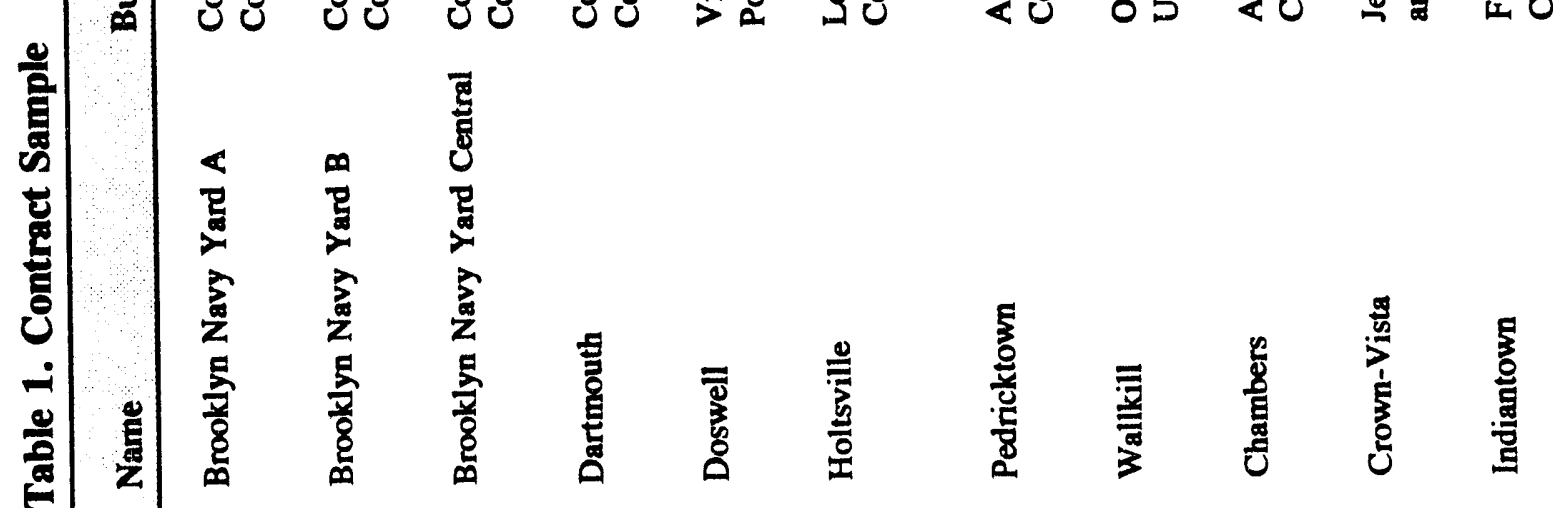




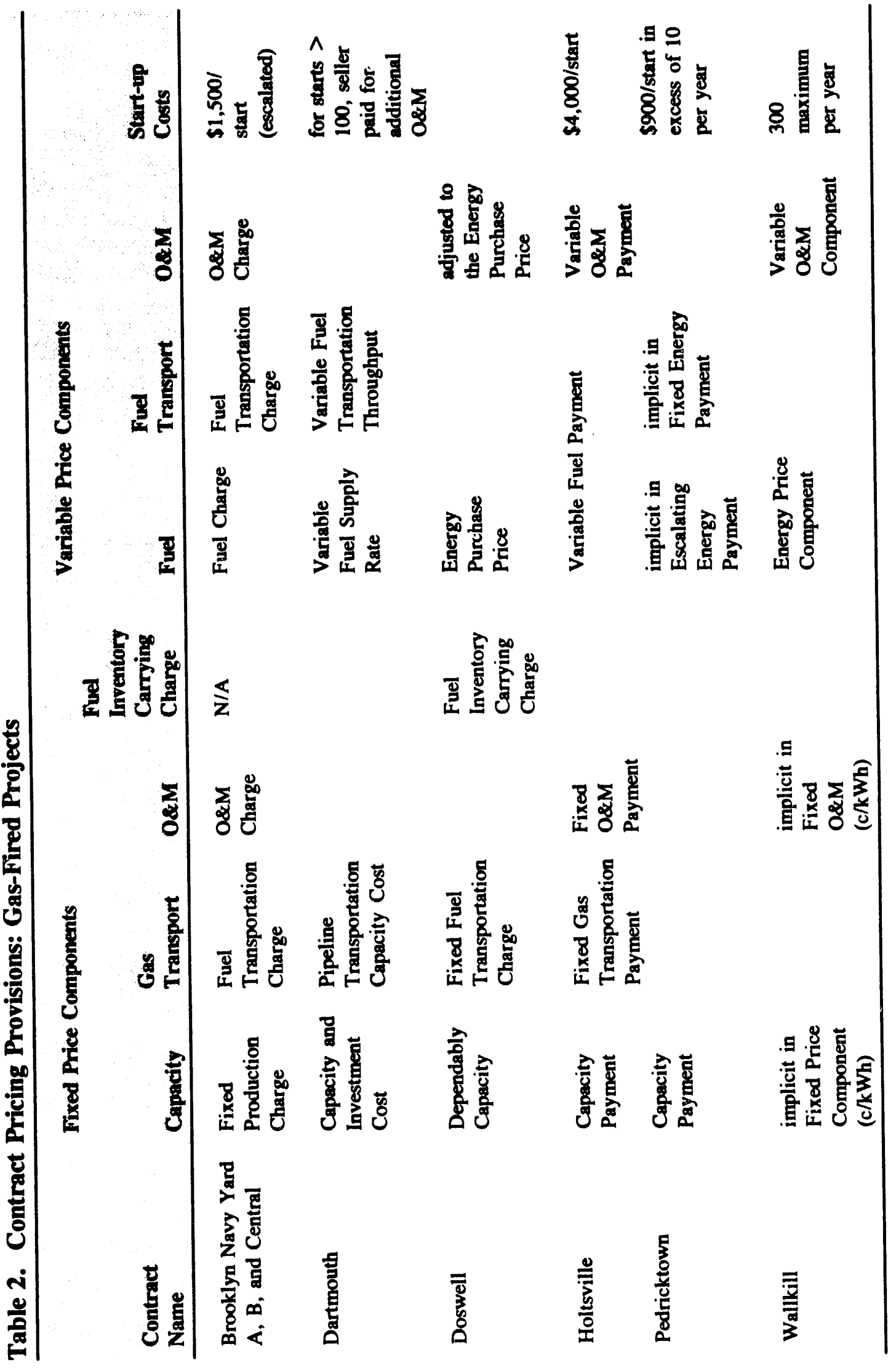


changes, as a result of implementing Order 636, are expected and will impact dispatchable projects particularly (Bowe, 1993).

\subsection{Gas-Fired Projects}

\section{Brooklyn Navy Yard (projects A, B, and Central)}

The three Brooklyn Navy Yard projects are very similar. All three are intended to have steam customers, and possibly other electricity sales. Projects A and B are both contracted to sell dependable summer capacity of $40 \mathrm{MW}$ to the utility. Project A was due to begin operation in May 1992, two years prior to project B, but otherwise the two projects are identical. The third project (Central) has a contracted capacity of $90 \mathrm{MW}$. In light of development delays, we assume that project A will start in May, 1994. All the plants may be dispatched by the Buyer at between $75 \%$ and $100 \%$ of capacity.

The Brooklyn Navy Yard projects receive both capacity and energy payments. The capacity (or fixed) component of the payment provisions includes a fixed production charge, a fixed operation and maintenance charge, and a fixed monthly fuel transportation charge. Capacity payments are based upon the summer dependable maximum net capability (DMNC), which is limited to the contracted capacity (i.e., $40 \mathrm{MW}$ for $\mathrm{A} \& \mathrm{~B}$, and $90 \mathrm{MW}$ for Central). The energy (or variable) co:nponent of the payment provisions includes a fuel charge, a fuel transportation charge, and a variable operation and maintenance charge. These payments are based on the amount of energy provided by the plants and may exceed the summer DMNC. Specifically, the contract indicates that Consolidated Edison (Con Ed) will purchase greater amounts of energy during the winter periods because of lower ambient temperatures and, thus, higher capacities. The contract does not specify the winter DMNC which establishes the upper bound upon the energy purchases, so we assume a $12 \%$ increase based on the capacity/temperature relationship specified in the Holtsville contract. ${ }^{2}$

In addition, the projects receive payments of $\$ 1,500$ per start-up directed by Consolidated Edison (the buyer), although the utility may request no more than 100 shut-downs and start-ups per year. Start-up costs have been ignored, but this omission is not expected to significantly affect our results. Start-up costs for pioject $\mathrm{A}$ are $\$ 4 / \mathrm{kW}$ in the first year for 100 starts, which is less than $1.5 \%$ of the fixed costs for that year. The number of start-ups would more likely be ten, since the projects variable costs are low compared to Con Ed alternatives. Ten starts would result in additional payments of less than $0.15 \%$ of fixed costs.

The most unusual aspect of the pricing in these three contracts is that the gas commodity prices escalate with an index related only to the Gross National Product Implicit Price Deflator, rather than an index which tracks gas commodity prices. This type of indexation for gas commodity

\footnotetext{
2 The summer rating of Holtsville is $136 \mathrm{MW}$, and the annual average rating is $152.5 \mathrm{MW}$. Therefore the average is $12 \%$ higher than the summer rating $(152.5 / 136=1.12)$.
} 
costs is unprecedented for contracts of this duration. Holtsville, for example, has a fixed gas commodity cost (i.e. zero indexation) but for only a five year period, and at a price substantially above expectations for spot gas at the start of that period. It is questionable whether GNP indexation of gas commodity costs would be sustainable over a thirty year contract term. One estimate of the price increase of these projects if standard fuel cost indexation mechanisms were used instead of the GNP formula is a premium of about $20 \%$ over the contract formula (Goldman et al., 1993).

\section{Dartmouth}

The Dartmouth contract disaggregates the fuel payments carefully, but includes the O\&M costs with the capacity costs. Payment consists of a capacity charge (which includes a capacity cost, an investment cost, and a pipeline transportation capacity demand cost) and an energy charge (which includes a variable fuel supply rate and a variable fuel transportation throughput rate). In the event that Commonwealth Electric (the buyer) requests more than 100 starts of the unit in one year, the capacity cost will be adjusted to reflect increased O\&M costs. However, the initial O\&M costs and the subsequent adjustment factors are not specified in the contract.

Dartmouth uses Canadian gas, transported by several pipelines from Alberta to Eastern Massachusetts. Gas transportation demand charges are calculated from the sum of charges for NOVA, TransCanada, and U.S. pipelines. Since the pipeline charges were not available, we used a levelized price estimate of the gas transportation charges of $\$ 151 / \mathrm{kW}$, rovided by the developer. The gas commodity price is indexed to a weighted average of Tennessee CD-6, Algonquin F-1 and Alberta Market Price for gas. Since the values for the index were not available, we used the actual gas costs for May 1992, the first month of operation. It is possible that the May 1992 price of \$1.67/MMBtu would not reflect seasonal variations in gas prices, but the developer indicated that this value was "typical." Moreover, this value is consistent with a gas price calculated using the contractually specified 1988 base rate of $\$ 1.35 / \mathrm{MMBtu}$ multiplied by our gas spot index of $1.051 \%$ over 4 years. Nonetheless, since the terms under which gas is supplied to the project are not known, and gas related costs comprise up to $60 \%$ of total cost, there could be significant error in the price calculated for this project. Finally, the variable fuel transportation throughput rate is based upon the NOVA, TransCanada, and U.S. pipeline throughput rates. We use an initial value of $\$ 0.25 / \mathrm{MMBtu}$ for the variable fuel transportation throughput rate, escalating with the GNP index, which was provided by the developer.

This project began operating in 1992. Therefore, we used data from the project developer to update contract language. The resulting pipeline demand charges were higher than estimated in the sample payment calculation given in the contract (up from about $22 \%$ of total cost to nearly $30 \%)$. The variable pipeline charges were lower (down from about $6.6 \%$ to $3.4 \%$ of total cost). 


\section{Doswell}

The Doswell projects consist of two plants with estimated dependable capacity of $275 \mathrm{MW}$ for the summer period and $330 \mathrm{MW}$ for the winter period. As ultimately determined by the testing procedures specified in the contract, the average capacity is $332.5 \mathrm{MW}$ for each plant, or 665 MW total. Since all price components are specified in the contract on a per $\mathrm{kW}$ basis, the difference between estimated and actual capacity should have no effect on unit price. In addition, the calculations assume $100 \%$ gas operation, which is what was intended for the project. Oil is strictly for back-up.

It is difficult to calculate the electricity price from the Doswell project with the information currently available. The payments consist of fixed payments for dependable capacity, fuel storage and transportation, and fuel holding and variable payments for fuel and operation and maintenance. The dependable capacity payments are specified contractually, but the fixed transportation and fuel holding costs are contractually indexed to the actual cost associated with transporting fuel to Chesterfield 7, a Virginia Power gas-fired combined cycle plant, and on the fuel inventory levels maintained for Chesterfield $7 .^{3}$ For the transportation costs, we estimated a cost of $\$ 30 / \mathrm{kW}$ (escalating with inflation) based on information from a Transco contract. This contract specifies the costs associated with the transportation of natural gas from Louisiana to Virginia, which we assume to account for most of the transportation charges. For the holding costs, we have used figures obtained from sample calculations included in the contract. Although the figure for holding costs may have changed, these costs comprise only a small portion of the total cost of electricity from the Doswell plant (e.g., about $\$ 2 / \mathrm{kW}$ in 1992).

While the fixed costs are relatively straightforward, the variable payments are somewhat problematic primarily because we do not know the relevant gas commodity and transportation costs. The "energy purchase price" is a function of a fixed heat rate and Chesterfield 7's delivered fuel price which includes variable gas transport charges (including surcharges like AGA, GRI etc.) and the transport and purchase cost for No. 2 oil. An operation and maintenance cost (in $\mathrm{c} / \mathrm{kWh}$ ) is also added to the energy purchase price. In addition, an adjustment to be determined by interconnection study will increase or decrease the energy purchase price to account for Doswell's effect on system losses.

It is not possible to estimate accurately the variable prices paid under this contract because we do not know the delivered cost of Chesterfield 7's fuel. The contract does contain a sample calculation of the different price components, but does not provide complete details. Nonetheless, we use this sample calculation as an estimate of the Chesterfield 7 delivered fuel price, although there is no guarantee that the numbers used in the example are now accurate. The data on 1992 Doswell performance and payments reported to the Virginia State Corporation Commission sheds some light on the price structure, but it is not without its ambiguity (Virginia Power, 1993). We summarize this data in Table 3 below.

\footnotetext{
${ }^{3}$ As a general principle, the Doswell contract is intended to mimic the costs of Chesterfield 7. This affects both fixed and variable price terms.
} 
Table 3. Doswell 1992 Revenue and Operation

\begin{tabular}{|c|c|c|c|c|c|c|}
\hline Contract & $\begin{array}{l}\text { Contract } \\
\text { Capacity } \\
\text { (MW) }\end{array}$ & $\begin{array}{c}\text { Energy } \\
\text { Purchased } \\
\text { (million kWh) }\end{array}$ & $\begin{array}{c}\text { Energy } \\
\text { Payments } \\
\text { (million \$) }\end{array}$ & $\begin{array}{l}\text { Capecity } \\
\text { Payments } \\
\text { (million \$) }\end{array}$ & $\begin{array}{c}\text { Average } \\
\text { Energy } \\
\text { Price } \\
(\$ / M W h)\end{array}$ & $\begin{array}{c}\text { Capacity } \\
\text { Factor** (\%) }\end{array}$ \\
\hline Doswell 1 & 333 & 426 & 11.82 & 27.42 & 27.8 & 20.6 \\
\hline Doswell 2 & 333 & 491 & 12.91 & 28.21 & 26.3 & 23.8 \\
\hline
\end{tabular}

Table 3 contains data for operations of approximately 8 months in 1992 because commercial operation began in early May (Miller, 1993). The capacity payments, on an 8 month basis, are equivalent to an annual payment of $\$ 125 / \mathrm{kW}$, which is approximately the contract price, excluding pipeline demand charges. These must be reflected in the energy payments, contrary to the contract language. Under some interpretations, the Table 3 data might suggest that variable cost was lower than the contract formula, but this cannot be determined from currently available data. ${ }^{4}$

\section{Holtsville}

The Holtsville project guarantees 136 MW of Dependable Maximum Net Capability (DMNC) at 91 degrees Fahrenheit during the summer on-peak period. The net dependably capability, however, varies considerably with the temperature. For our calculations, we have used the net dependable capability of $152 \mathrm{MW}$ at the average temperature of 51 degrees Fahrenheit, rather than the lower capability that occurs only during the hotter summer peak periods. For this project, Long Island Lighting Company (the buyer) may interrupt electricity delivery from the Holtsville project for up to 5000 hours per year. This is equivalent to a minimum cipacity factor of $43 \%$ (assuming no forced outages during run time, and $100 \%$ capacity factor when operating).

Payments are fully disaggregated and detailed methods for determining gas prices are set. The fixed payments include a capacity payment, a fixed gas transportation payment, and a fixed operation and maintenance payment. The capacity payments and O\&M payments are specified contractually. The fixed transportation payment, however, depends upon FERC D-1 and D-2 demand charge rates. FERC, however, has since adopted a new rate structure and the new combined D1 \& D2 rates were obtained from the New York Power Authority and multiplied by

\footnotetext{
4 Suppose we assume that pipeline demand charges are $\$ 30 / \mathrm{kW}$ yr. For 8 months this would be $\$ 20 / \mathrm{kW}$ assuming uniform monthly pricing. At an average $22 \%$ capacity factor, $\$ 20 / \mathrm{kW}$ is equivalent to $\$ 10.4 / \mathrm{MWh}$. Netting this out from the Table 3 average energy prices results in a fuel related cost of about $\$ 17 / \mathrm{MWh}$, compared with a contract related estimate of about $\$ 21.5 / \mathrm{MiWh}$.
} 
the transportation quantity. Firm gas transport is the intention, but the seller must have permits to operate for 30 days per year on oil, and is to make best efforts to obtain permits for 60 days of oil operation.

The variable price provisions include fuel (and transportation) payments and operation and maintenance payments. The fuel and transportation payments depend upon the gas price and the gas used to operate the facility. The gas price combines many elements including the gas commodity price (which is set at $\$ 3.53 / \mathrm{MMBtu}$ for the first years of the contract), the interstate pipeline commodity charges, local delivery charges, etc. We obtained these figures from the New York Power Authority. One gas price formula is used until January 2001, another until January 2006, and a third from then until the end of April 2014 (end of contract). The gas price assumed in the calculations for this study is based on a continuation of the second gas price formula but using the standard assumption for commodity inflation, resulting in a 2006 gas commodity price of $\$ 4.78 / \mathrm{MMBtu}$. The variable O\&M payments are based on the number of operating hours and the number of start-ups. Thirty-eight start-ups per year were assumed, corresponding to a weekend shutdown operating schedule combined with shutdown during the spring and fall low load periods. For this project, including an estimate of start-up costs has a significant effect on price, especially for low capacity factors (at $40 \%$ capacity factor, price would be $0.4 \mathrm{c} / \mathrm{kWh}$ lower if we ignored start-up costs).

The Holtsville contract contains an option clause that allows the utility to substitute its own gas for that which would otherwise be supplied by NYPA for the project. If this option is invoked, however, it is not clear that the net cost of power from the project would be any less than under the standard formula. The reason is that the utility will still be obligated to pay for the pipeline demand charges even if they take no gas (Kerr, 1993). The utility will also have to pay for gas transportation, even if they use their own commodity gas. Therefore, the difference in commodity cost between the NYPA price and the utility price would have to be greater than the fixed pipeline demand charges for there to be any net savings. The calculations in the appendix show that for the first year of the contract pipeline costs are approximately one third of total energy costs at $85 \%$ capacity factor. This means that utility commodity gas prices must be more than $\$ 1$ per mi!! ion Btu cheaper for there to be any net savings. Even if this were true for one year, it is unclear that it would persist long enough to make a substantial change in lifecycle levelized price. Therefore we neglect the effect of the option clause.

\section{Pedricktown}

This contract sets a capacity payment and then gives the seller a choice of two different pricing mechanisms for energy payments. We describe the energy pricing mechanism selected by the seller. The energy price formula is separated into on-peak and off-peak payments. Further, each payment contains a fixed price per $\mathrm{kWh}$ plus an escalating per $\mathrm{kWh}$ price, where the escalation is based on the cost of natural gas to N.J. utilities for the previous year compared with 1991 gas costs. The index for the first year (1992), therefore, is equal to one. Since this study assumes an increase in gas cost with the "gas spot index" after year one, the gas costs used in 
this study may be higher than the actual costs for the project. For start-ups in excess of 10 per year, the cost per start is $\$ 900$ escalated with CPI. We have omitted these costs from our calculations.

The contract specifies a minimum of 3500 hours run time (similar to Holtsville), at least $58 \%$ of which must be on-peak. For our calculations, we have assumed that all hours run are on-peak up to the maximum of 5,110 on-peak hours.

\section{Wallkill}

All contract pricing terms in the Wallkill contract are given in cents per $\mathrm{kWh}$ and differ for "must run" and "non-must-run" hours. "Must run" hours include all on-peak and shoulder peak hours and a minimum number of off-peak hours. We have estimated that the project will have 4,760 must-run hours. The number of non-must-run hours will depend upon the actual dispatch of the project.

For "must-run hours" the price consists of a fixed price component (given for each year), a variable O\&M cost indexed to CPI, a fixed O\&M cost indexed to CPI, and an energy component indexed to a spot market gas price. For the energy price calculations, we use a 1994 average gas price of $\$ 2.05 / \mathrm{MMBtu}$ provided by U.S. Generating Company and escalate this price using the assumed "gas spot index". For "non-must-run hours" the price to be paid is the actual incremental cost (including incremental fuel costs, labor costs and other operating and maintenance costs) plus a margin of 0.25 cents per $\mathrm{kWh}$ (or lower). We use the energy and variable $0 \& M$ costs plus 0.25 cents as a proxy for the incremental costs. The contract does not mention any escalation of the margin, and none has been included here. No explicit mention is made in the contract of gas transport costs, fixed or variable, although presumably these costs are bundled in the fixed and energy price components.

\subsection{Coal-Fired Projects}

\section{Chambers}

Similar to the Pedrickstown contract discussed above, the Chambers contract with Atlantic City Electric Company also contains a set capacity payment, but offers the seller a choice of two different pricing mechanisms for energy payments. We describe the method which has an explicit pricing formula. The agreement has a set capacity payment of $\$ 316 / \mathrm{kW}$-year, but divides the energy payments into on-peak and off-peak payments. Each of these energy payments also has a fixed portion and an escalating portion. Escalation is based upon the average cost of coal to N.J utilities for the previous year compared with 1992 coal costs. Thus, the index for the first year (1993) is equal to 1. As discussed previously, we assume that coal costs with escalate with inflation. 
The contract also specifies a minimum of 3,500 hours run time, at least $58 \%$ of which must be on-peak. For purposes of our calculations, we have assumed that all hour run are on-peak up to the maximum of 5,110 on-peak hours. Start-up payments of $\$ 900$ each are specified in the contract for start-ups in excess of 10 per year; these are ignored in our calculations.

\section{Crown-Vista}

The Crown-Vista contract contains relatively straight-forward, but bundled payment provisions. The payments include a fixed payment, a variable energy payment, and start-up payments. The fixed payment includes a portion that does not vary over time and a portion that escalates with inflation. The escalating portion of the fixed payment most likely represents fixed operation and maintenance costs. The variable energy payment also escalates with inflation and likely encompasses the variable fuel, transportation, and operation and maintenance expenses. Startup payments are set at $\$ 35,320$ per start-up, but are excluded for the purposes of our calculations in order to be consistent with the other contracts and because it is unlikely that the buyer will request many start-ups and shut-downs for a baseload coal-fired power plant.

\section{Indiantown}

The Indiantown contract has somewhat complex pricing provisions. It divides its payments into capacity and energy payments. The capacity payments differ according to the "capacity billing factor." For example, capacity payments are $\$ 0 / \mathrm{kW}$ with a capacity billing factor less than $55 \%$, but $\$ 372 / \mathrm{kW}$ with a capacity billing factor that is greater than $97 \%$. The "capacity billing factor" is itself quite complex. It is defined as the annual capacity factor, plus half the difference between the annual on-peak capacity factor and $93 \%$. The annual capacity factor in term is defined based upon the daily capacity factor and, finally, the daily capacity factor essentially equals the sum of the energy purchased plus the energy that was not but could have been delivered divided by the product of the committed capacity and the available run hours (which exclude scheduled maintenance). In our calculations, we use the term capacity factor to mean the actual production divided by 8760 (hours in the year) times the rated capacity. The capacity factor in the Indiantown contract functions more as an availability factor. Thus, in order for our calculations to be consistent, we have estimated an acceptable "capacity billing factor" or what we would refer to as an availability factor. We have chosen a $95 \%$ availability factor, which yields a capacity payment of $\$ 358 / \mathrm{kW}$-year. ${ }^{\$}$

The energy payment in the Indiantown depends upon a unit energy cost and unit energy efficiency. The unit energy cost equals $\$ 23.20 / \mathrm{MWh}$ (in 1990\$) and is indexed by the change in FOB mine spot prices and other cost components (i.e., transportation, lime supply and ash disposal). We have indexed this unit energy cost with an inflation index. For purposes of our

\footnotetext{
'An "availability factor" of $85 \%$ would yield a price of $\$ 325 / \mathrm{kW}$-year, while $90 \%$ would yield $\$ 338 / \mathrm{kW}$-year, and $100 \%$ would yield $\$ 372 / \mathrm{kW}$-year.
} 
calculations we have used a unit energy efficiency factor of 1 recognizing that we may be understating the actual electricity prices. The purpose of the unit efficiency factor appears to be to compensate the seller for operating inefficiencies that result when the plant is operating at less than full load. In the extreme, the unit efficiency factor is 1.23 when the plant is operated at a 33.5\% load factor. In our calculations we have neglected the unit efficiency factor which would make the electricity prices for the project more expensive at lower capacity factors. We have omitted this factor for two reasons. First, when we calculate the electricity prices for different capacity factors we are not necessarily assuming that the plant is operating at less than full load; the low capacity factor also could result from shut-downs. Second, while inclusion of the unit energy efficiency factor would make electricity prices more expensive, we believe that this might be offset by the lower prices that would result from the fuel cost sharing arrangement where Florida Power \& Light (FPL) and the seller share the difference between the actual and adjusted energy costs. We have also neglected the potential electricity price reductions resulting from this fuel cost sharing arrangement.

\section{$5 \quad$ Results}

\section{Price Estimates}

We present the results of our calculations in Table 4. Details are given in the Appendix, including all contract terms, specific assumptions, and an explicit cost calculation for operation at $85 \%$ capacity factor and low gas prices. The first set of figures is for a low gas price forecast, where we assume that gas commodity prices will rise at $5.1 \%$ per annum (inflation plus $1 \%$ ). The second set of figures is for a high gas price forecast, where we assume that gas commodity prices will rise at $7.1 \%$ per annum (inflation plus $3 \%$ ). We have sorted these figures according to the levelized costs at an $85 \%$ capacity factor. The cost curves for each of these projects are illustrated in Figures 1 and 2. Figure 1 contains the costs curves using the low gas price forecast, and Figure 2 contains the cost curves using the high gas price forecast. Notice that in each figure, there are price curves which cross one another. Such crossings show the necessity for representation of the complete curve, rather than collapsing price into a one-dimensional measure. There is no way to know ex ante whether such crossings would occur or not.

The results do not show that the "law of one price" is operative in this market yet. We discuss this in Sections 6 and 7 below. Roughly speaking the projects divide into a high, a low and a medium priced group. The high priced projects are Holtsville, Dartmouth, Indiantown, Pedricktown and Chambers. Doswell, Brooklyn Navy Yard Central and Wallkill are a low priced group. Crown-Vista and the other two Brooklyn Navy Yard projects are in the middle of the range.

The average price of the gas-fired projects (unweighted by capacity) for $85 \%$ capacity factor is $7.0 \mathrm{c} / \mathrm{kWh}$ at low gas prices and $7.4 \mathrm{c} / \mathrm{kWh}$ at high gas prices. The high gas price scenario 
Figure 1. Contract Prices at Various Capacity Factors (with high gas price forecast)

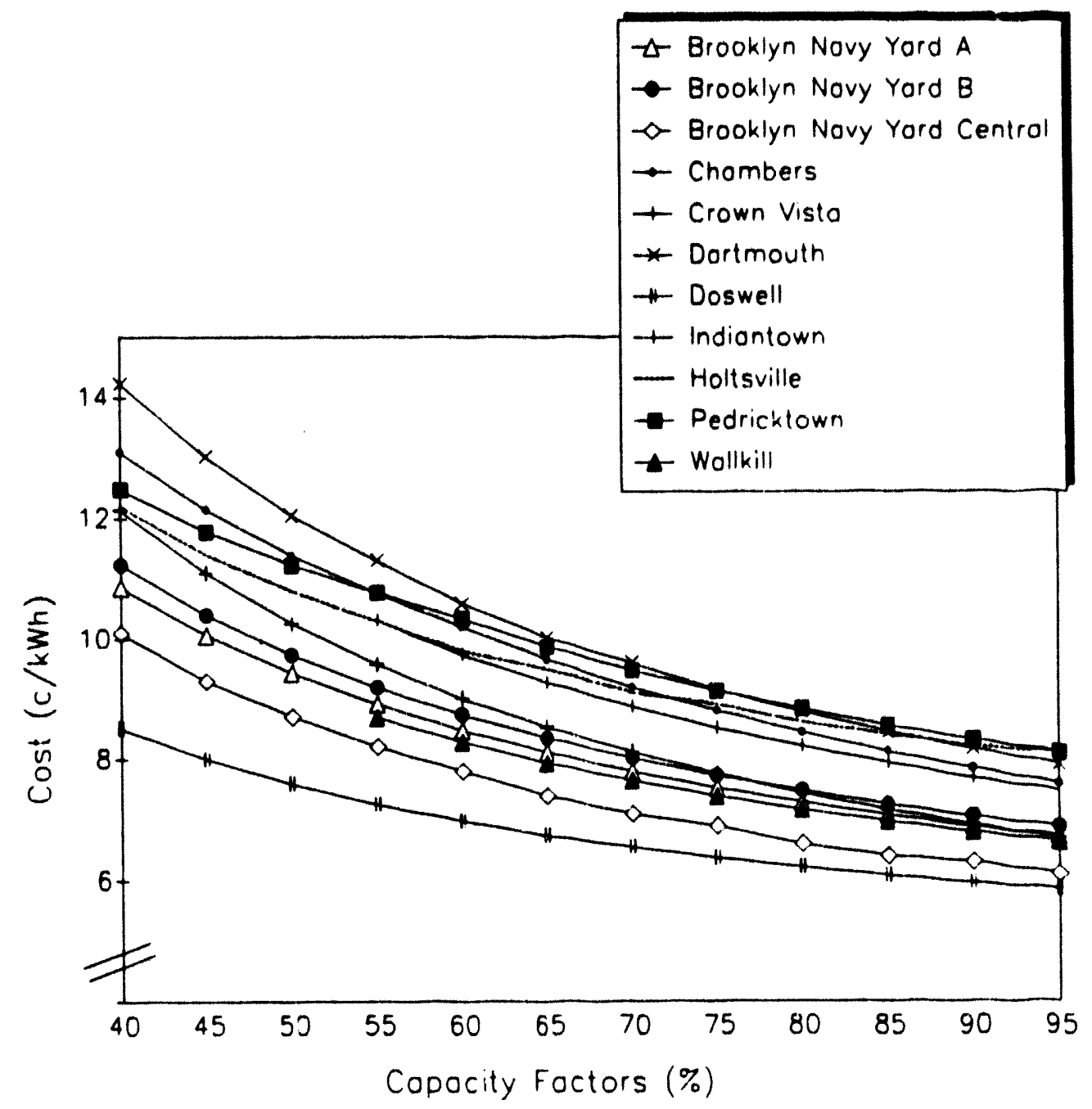


Foure 2. Contract Prices at Various Capacity Factors (with low gas price forecest)

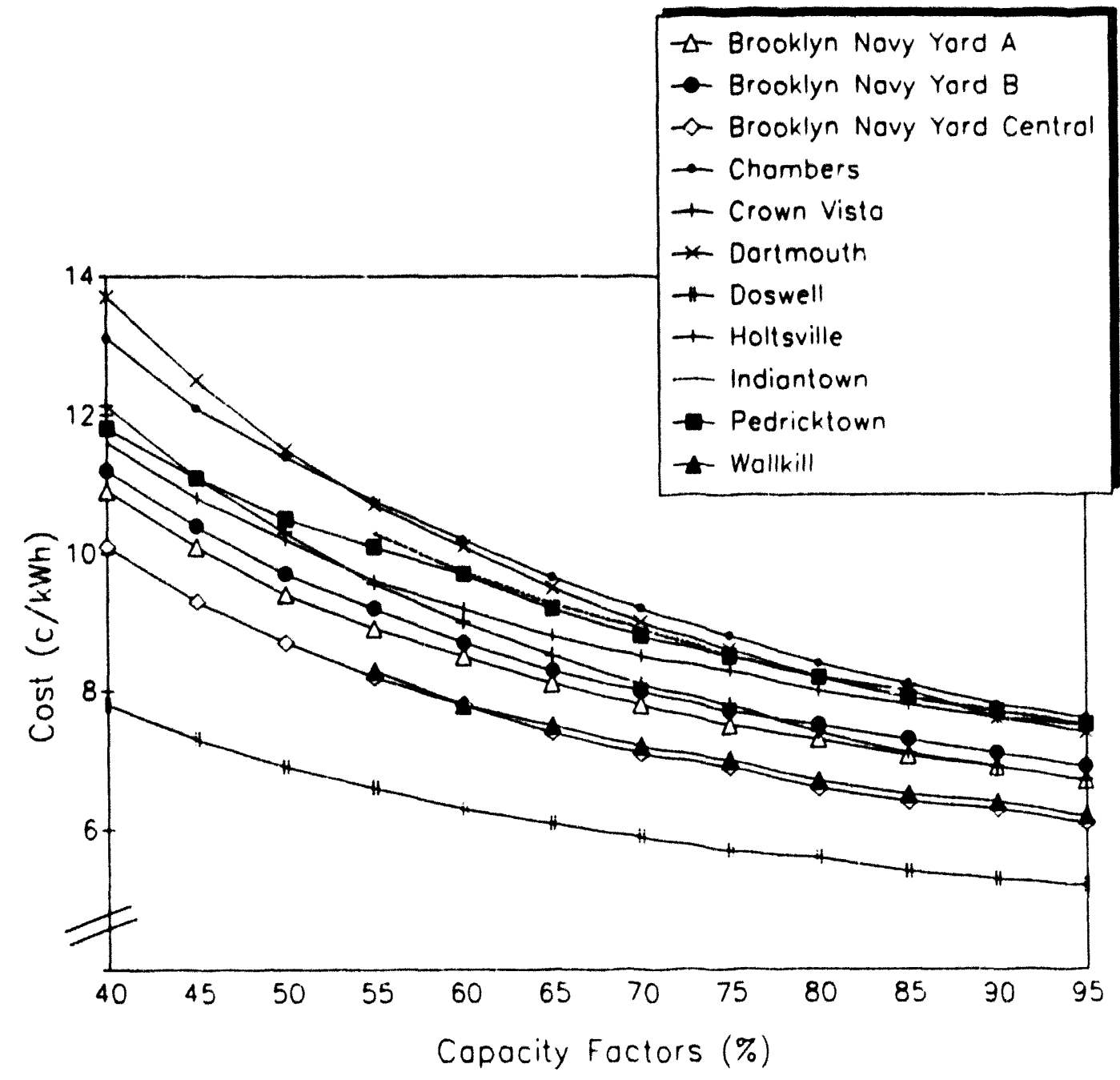




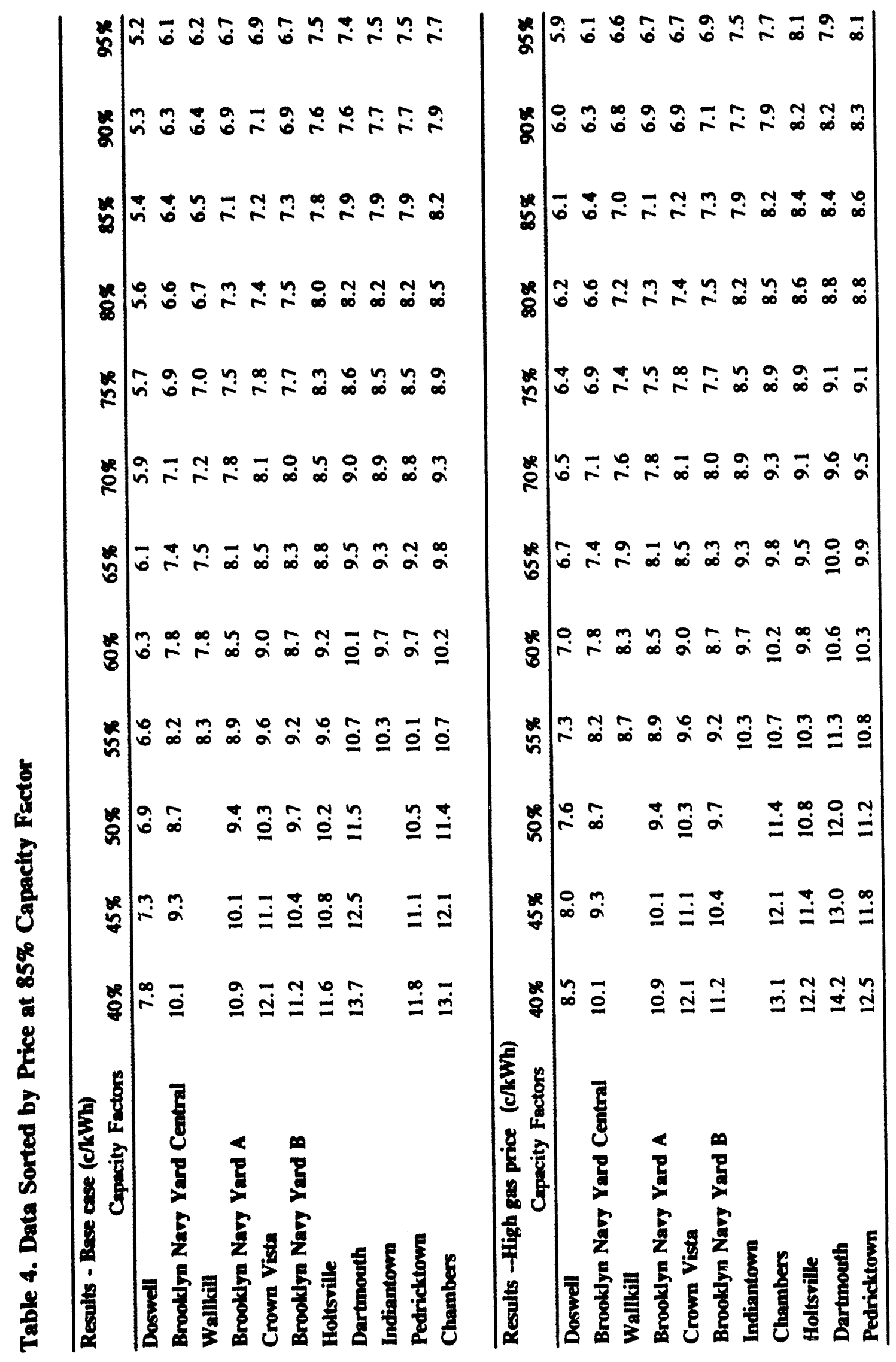


increases price by $0.5-0.7 \mathrm{c} / \mathrm{kWh}$ for the five projects that have fuel prices indexed to the gas spot market. The coal projects average $7.7 \mathrm{c} / \mathrm{kWh}$. The variation among the gas projects is much greater than among the coal projects.

Because fixed price components play a large role in the cost structure of all of these projects, the spread of prices is greater at lower capacity factor than at higher capacity factor. The unbundling of gas prices contributes to the similarity in price structure of solid fuel and gas-fired projects; i.e. both project types have very substantial fixed cost components, regardless of actual production.

\section{Caveats}

These levelized cost calculations should be interpreted with some caution. These figures represent an initial attempt to estimate the costs associated with various gas-fired and coal projects, but some uncertainties and unresolved issues remain.

First, there are substantial uncertainties associated with the gas prices used in our calculations. In many contracts, gas prices, or fuel costs more generally, are tied to a particular gas commodity price index or a combination of indices. We have simply assumed a 5.1 percent increase over the term of the contract. It is not clear, however, that gas prices are in fact rising as we have assumed. Nonetheless, while it is likely that our gas price forecasts will miss the mark, we have at least applied a consistent assumption across contracts (i.e., that all gas prices will rise by the same percentage each year). A more thorough investigation of the indices in these projects, verifying their performance in the interval between contract signing and this analysis, might result in some downward adjustments to the price estimates. This would occur because spot commodity costs for natural gas have been increasing at less than the assumed $1 \%$ real rate. This would affect contracts which were signed at earlier dates more (such as Doswell) since our assumed escalation would be too great compared to the market (see the discussion of Table 3 and note 4 ).

Second, there are also substantial uncertainties associated with gas transport prices because transport pricing structures are changing and some of this information is not publicly available. Two contracts are illustrative. In the Holtsville contract, the contract indicated that the transportation costs would depend upon D-1 and D-2 gas demand charge rates, but FERC subsequently combined these rates. In effect, these changes resulted in higher demand charges and lower variable transportation charges than initial anticipated in the sample calculations. In the Doswell contract, fixed transportation charges depend upon the actual transportation prices associated with transporting gas to Chesterfield 7. However, the contract does not fully delineate all of the associated costs, nor was this information publicly available. Thus, we relied upon information from a Transco contract that provided estimates of the transportation costs associated with the transportation of natural gas from Louisiana to Virginia. 
Third, some projects have or will miss their start dates and it is not clear how this will affect contract prices and whether some pricing provisions will be renegotiated.

Fourth, we have not yet developed a methodology for comparing costs across contracts with different lengths. The issue is important because the cost and the value of electricity to the utility differ. The value of electricity is typically represented by the avoided cost of supply and is usually higher than the cost paid by the utility to the IPP. Thus, projects that operate more hours or for longer terms generally provide more value (or net benefits) to the utility. One way to correct for this "end effects" problem would be to determine the utilities next best source of electricity at the end of the contract term and to incorporate the price for the alternative source into the shorter duration contracts. In practice, this exercise is complicated because it is difficult, if not impossible, to determine the utilities next best source of utility generation 10 to 20 years in the future.

\section{Towards an Explanatory Theory of Prices}

In a perfectly functioning, i.e. competitive, market the only differences in price for the same commodity should be transportation costs, which reflect separation between the production and consumption centers. When market prices show greater variability than can be explained by transportation costs, some form of market power, either on the buyer or seller side, is usually the cause. ${ }^{6}$

In this section, we enumerate the kinds of causal factors that could account for a good deal of the observed variation in prices that emerge from this analysis. Indeed, one long range analytic goal of the work described here would be to construct an explanatory model of private power prices. It is premature to attempt such a model. Nonetheless, some of the pattern we observe in this small sample can be accounted for by enumerating factors that are likely to be significant in a more systematic analysis. Some of these factors are relevant to cust differences (scale and geography), some are relevant to market characteristics. This discussion is somewhat speculative, but it is designed to illustrate the kinds of issues that must be confronted to make meaningful uses of the price data that is emerging from competitive processes in the electricity market.

\footnotetext{
There is a large literature on industrial organization which discusses these issues including the welfare and efficiency effects of different kinds of deviations from the perfectly competitive ideal (Scherer, 1980; Tirole, 1988).
} 


\section{Scale Economies}

There are substantial scale economies even in projects based on combustion turbine technology. Recent literature on advanced gas turbines emphasizes their suitability and attractive economics for small scale applications (Kolp and Moeller, 1988; Williams and Larson, 1989). Nonetheless, trade press reports on recent large scale combined cycle cogeneration projects show very low unit costs for large projects. One example is the recently financed Independence Cogeneration Project, whose 1000 MW capacity cost approximately $\$ 800 / \mathrm{kW}$ (Beck, 1993). More recently, the Teeside project, under construction in England, is claimed to have a $\$ 1.2$ billion cost for $1875 \mathrm{MW}$, or approximately $\$ 640 / \mathrm{kW}$. Projects in the $200-400 \mathrm{MW}$ range are typically estimated to have costs approximating $\$ 1000 / \mathrm{kW}$.

While systematic cost data on private power projects is unavailable, these reports from industry publications suggest that scale economies are significant. This factor is one reason why the Doswell project, at $600 \mathrm{MW}$, is the lowest cost member of our contract sample, all the rest of which are smaller than $150 \mathrm{MW}$.

Given that scale economies exist, the choice of project size is endogenous to the market behavior. Why do some buyers choose large projects and some choose small ones?

\section{Geographic Factors}

There are a number of reasons why projects built in some regions should have higher costs than those built in other regions. These factors include: land costs, environmental restrictions, wage rates, and proximity to fuel supply. For the projects in our sample, we would expect all of these regional factors to raise the costs of Dartmouth, located in Massachusetts, compared to Doswell, located in Virginia. Generally speaking, the New England region has high land and labor costs, considerable environmental restrictions and is remote from sources of natural gas. By comparison, Virginia may be more favorably situated on all these factors. However, Doswell, for example, is required to meet very strict emissions restrictions for $\mathrm{NO}_{\mathrm{x}}(9 \mathrm{ppm}$ using natural gas and $65 \mathrm{ppm}$ using oil) (Makansi and Collins, 1993). These are comparable to strict California emissions requirements (Kolp and Moeller, 1988).

Transmission costs should, in principle, set an upper bound on the range of price variation observed between regions. Our results show a price spread of $2.5 \mathrm{c} / \mathrm{kWh}$ at $85 \%$ capacity factor, and $2.2-2.3 \mathrm{c} / \mathrm{kWh}$ at $95 \%$ capacity factor. This is greater than the cost of new long distance high voltage transmission. For example, an 800 mile $500 \mathrm{kV}$ transmission line coming into service in the mid 1990s might cost $2 \mathrm{c} / \mathrm{kWh} .^{?}$

\footnotetext{
${ }^{7}$ Typical construction costs for new $500 \mathrm{kV}$ transmission is $\$ 1 / \mathrm{kW}$-mile (Baldick and Kahn, 1992). The present value revenue requirements for such investments would be no more than $\$ 1.50 / \mathrm{kW}$-mile. Total revenue requirements for an 800 mile line would be $\$ 1200 / \mathrm{kW}$, or $\$ 0.137 / \mathrm{kWh}(=\$ 1200 / 8760)$. The annual fixed charge for this would be roughly $2 \mathrm{c} / \mathrm{kWh}$ (at a fixed charge rate of 0.15 ).
} 


\section{Buyer Characteristics}

There are several features of buyers that may influence price. Small utilities may have less bargaining power than larger firms. This difference has its origin partially in the broader opportunities available to large firms, and partially in their greater sophistication. There may also be a price effect stemming from the influence of regulatory preferences in the contracting and procurement process. States where the regulator rigidly specifies the terms of competition and acquisition may end up paying higher prices than states where substantial discretion and bargaining power is delegated to utilities (Jurewitz, 1993). Finally, there is an issue involving transactions between utilities and affiliates. There have been several widely publicized cases where such transactions have been perceived by regulators to be priced too high (CPUC, 1990; Stone and Webster, 1991).

In our sample, we have one affiliate transaction (Pedricktown), cases where the regulator played a substantial role in the procurement process (Consolidated Edison), and a number of small utility buyers (Commonwealth Energy, Orange and Rockland and Atlantic Electric).

\section{Seller Characteristics}

Some sellers may be in a position to offer lower prices than others due to particular circumstances. One example, illustrated in our contract sample, is a government entity acting as seller. The Holtsville project is being developed by the New York Power Authority (NYPA). Since NYPA has access to tax exempt financing and need not use expensive common equity, its cost of capital will be lower than private producers. This should be reflected in lower prices.

Another seller characteristic that may contribute to lower prices is the "merchant IPP" phenomenon. This describes a project that has capacity larger than the contract capacity specified in the particular transaction being analyzed. Such projects are constructed in anticipation of subsequent sales that will utilize the remaining capacity. These projects can then capture scale economies, which will presumably be reflected in prices. If the scale economy variable is ascribed only at the level of contracts, rather than projects, such effects will be missed. In our sample, Wallkill is an example of this phenomenon (Independent Power Report, 1992).

\section{Concluding Thoughts: Price vs. Value}

The approach to analyzing price variation outlined in Section 6 focused on observable characteristics, and the assumption that the projects represent a homogeneous product. An alternative, or perhaps complementary, explanation of observed price variation should account for the possibility that the projects are not a homogeneous product. One dimension along which generation projects are differentiated is their expected function in the dispatch process. Different dispatch "niches" (commonly referred to as baseload, intermediate or peaking) amount to 
different generation products, whose value, and hence whose price (and cost) can be expected to differ.

As a first approximation to even simple comparisons, attention should focus on some notion of expected levels of dispatch. The levelized prices illustrated in Section 5 are the sum of fixed and variable terms. It is the variable price which determines dispatch (to the degree this is contractually permitted). In general, projects with similar variable costs should be expected to operate similarly; they are selling the same "product." In our sample, Dartmouth and CrownVista have the lowest variable prices and can be expected to operate the most. At the other extreme, Holtsville and Pedricktown have the highest variable prices and should operate the least. The actual operation will depend upon the opportunity cost situation of the purchasing utility, i.e. the variable costs of other resources available to serve demand. Any simple comparison ought to take account of both the variable costs of projects and the opportunity costs of the buyer. The reason that value comparisons are difficult is that information on variable costs is difficult to obtain systematically and not easily amenable to the construction of a value metric. ${ }^{8}$

If we had a sample of projects that all sold power in the same regional market, with approximately similar variable costs, and hence similar expected dispatch, then price comparisons would be useful. Such situations may well arise if FERC, for example, wanted to evaluate a market determined pricing arrangement by using a "benchmark" type of comparison.

At the current stage of development, such comparison would not be very meaningful. With a larger sample, more analysis of the benchmark kind (i.e. similar variable costs, same regional market) could be undertaken. With larger samples, the kind of analysis outlined in Section 6 above would start to become feasible.

In this paper, we have shown that it is feasible to analyze private power prices systematically. We have illustrated our method, and given concrete examples of the kind of problems that arise in such analysis. This is only an initial effort; a proof of concept. Given the changing nature of the long-term electricity markets, it would be useful to begin collecting contract price data systematically.

\footnotetext{
- Value comparisons lie at the heart of the competitive bidding framework out of which most of these projects arise. See Stoft and Kahn (1991) for a treatment of the value issues.
} 


\section{Acknowledgements}

We have received information from many people, whom we hereby thank. They include Lou DeCiccio, Atlantic Electric; James Doggart, EMI Dartmouth Associates; William Garrett, Mission Energy; Andrew Harvey, New York Public Service Commission; Margaret Jess, Federal Energy Regulatory Commission; Gregory Kelly and Lisa Hopkins, U.S.Generating Company; Douglas Kerr, New York Power Authority; Steven Miller, Diamond Energy; Ishwara Raju, Virginia Corporation Commission; Richard Realmuto and Chris Trabold, Long Island Lighting Company; and Jim Weller, Cogeneration Partners of America.

The work described in thi: report was funded by the Assistant Secretary for Energy Efficiency and Renewable Energy, Office of Utility Technologies, Office of Energy Management and the Assistant Secretary for Fossil Energy of the U.S. Department of Energy under Contract No. DEAC03-76SF00098. 


\section{References}

Baldick, R. and E. Kahn, Transmission Planning in the Era of Integrated Resource Planning: A Survey of Recent Caces, LBL-32231, 1992.

Beck, R.W. and Areociates, Independent Engineer's Report Independence Cogeneration Project, 1993.

Bowe, J., "Natural Gas, Power Generation and Order No. 636: Regulatory and Commercial lesues That Muat Be Addreseed For the Courtship to Lead to Consummation," Record of Proceedings: Conference on Nasural Gas Use, State Regulation and Market Dynamics in the Post 636/Energy Policy Aat Era, DOE/CONF. 930289, 1993.

Califomia Public Utilities Commission (CPUC), Docision No. 90-09-088, 1990.

De Vany, A. and W. Walls, "When Barriers to Markets Fall: Deregulation, Spot Markets, and the Topology of the Natural Gas Market," University of Califomia Transportation Center Working Paper No. 123, 1992.

Ellis, L., Testimony on behalt of Virginia Power in Virginia Corporation Commission Case No. PUE890051, 1989.

Energy Information Administration (EIA), Growth in Unbundled Natural Gas Transportation Services: 1982-1987, DOE/EIA-0525, 1989.

Energy Information Administration (EIA), Natural Gas 1992 lssues and Trends, DOE/EIA-0560(92), 1993

Federal Energy Regulatory Commission (FERC), Pipeline Service Obligations and Revisions to Regulations Governing Self-Implementing Transportation Under Part 284 of the Commissions Regulations, Docket No. RM91-11-D00 and Regulation of Natural Gas Pipelines After Partial Decontrol, Docket No. RM87-34-065, Order No.636 Final Rule, 1992.

Goldman, C., J.Busch, E.Kahn, R.Baldick and A.Milne, Review of Consolidated Edison's Integrated Resource Bidding Program, LBL-33599, July, 1993.

Independent Power Report, 110 Independent Power Companies: Profiles of Industry Players and Projects, McGrawHill Inc. 1992.

Jurewitz, J., "Life After the Energy Policy Act of 1992," The Electriciny Journal v.6, no.5 (1993) 48-65.

Kahn, E. "Risks in Independent Power Contracts: An Empirical Survey," The Electricity Journal v.4, no.9 (1991) $30-45$.

Kahn, E., C.Marmay and D.Berman, "Evaluating Dispatchability Features in Competitive Bidding," IEEE Transactions on Power Systems, v.7, no.3 (1992a) 1259-1265.

Kahn, E., M. Meal, S. Doerrer and S. Morse, Analysis of Debt Leveraging in Private Power Projects, LBL-32487, $1992 b$.

Kert, D., New York Power Authority, personal communication, 1993. 
Kolp, D. and D.Moeller, "World's Firat Full STIG LMS000 Installed at Simpson Paper Company," Transactions of ASME Journal of Engineering for Gas Turbines and Power, v.111, no.2 (1988) 200-210.

Lyon, T. and S. Heckett, "Bottlenecks and Governance Structures: Open Acceses and Long-Term Contracting in Natural Gas," Indiana Univeraity Working Paper, 1993.

Makanai, J. and S. Collins, "Dispatchable Power: Doswell Anowers the Call," Power, v.137, no.4 (1993) 27-28.

Miller, S, Diamoad Energy, perconal communication, 1993.

National Independent Energy Producers (NIEP), Negotiating Risk: Efficiency and Risk Sharing in Electric Power Markets, 1992.

Ocean Sule Power II (OSP), S9 FERC $\{61,360$ at 62,323-4 (1992).

Scherer, F. Industrial Market Structure and Economic Performance, econd edition. Rand McNally, Chicago,ILL. 1980

Stof, S. and E.Kahn, "Auction Markets for Dispatchable Power: How to Score the Bids," Journal of Regulatory Economics, v.3, no.3 (1991) 275-286.

Stone and Webster Management Consultants, Feasibility Report for the Midland Cogeneration Venture, 1991.

Toco Power Services and Tampa Electric Company (TECO), 52 FERC 1 61,191, 1990.

Tirole, J. The Theory of Industrial Organization. MIT Press, Cambridge, MA, 1988.

Virginia Power, Annual Filing Pursuant to Case No. PUE800102, March 1, 1993.

Williams, R. and E.Larson, "Expanding Roles for Gas Turbines in Power Generation." Electriciry: Efficient EndUse and New Generasion Technologies, and Their Planning Implications. T.Johansson, B.Bodlund and R.Williams ods. Lund University Press, 1989. 


\section{Appendix A}

Price Calculation for Individual Projects 


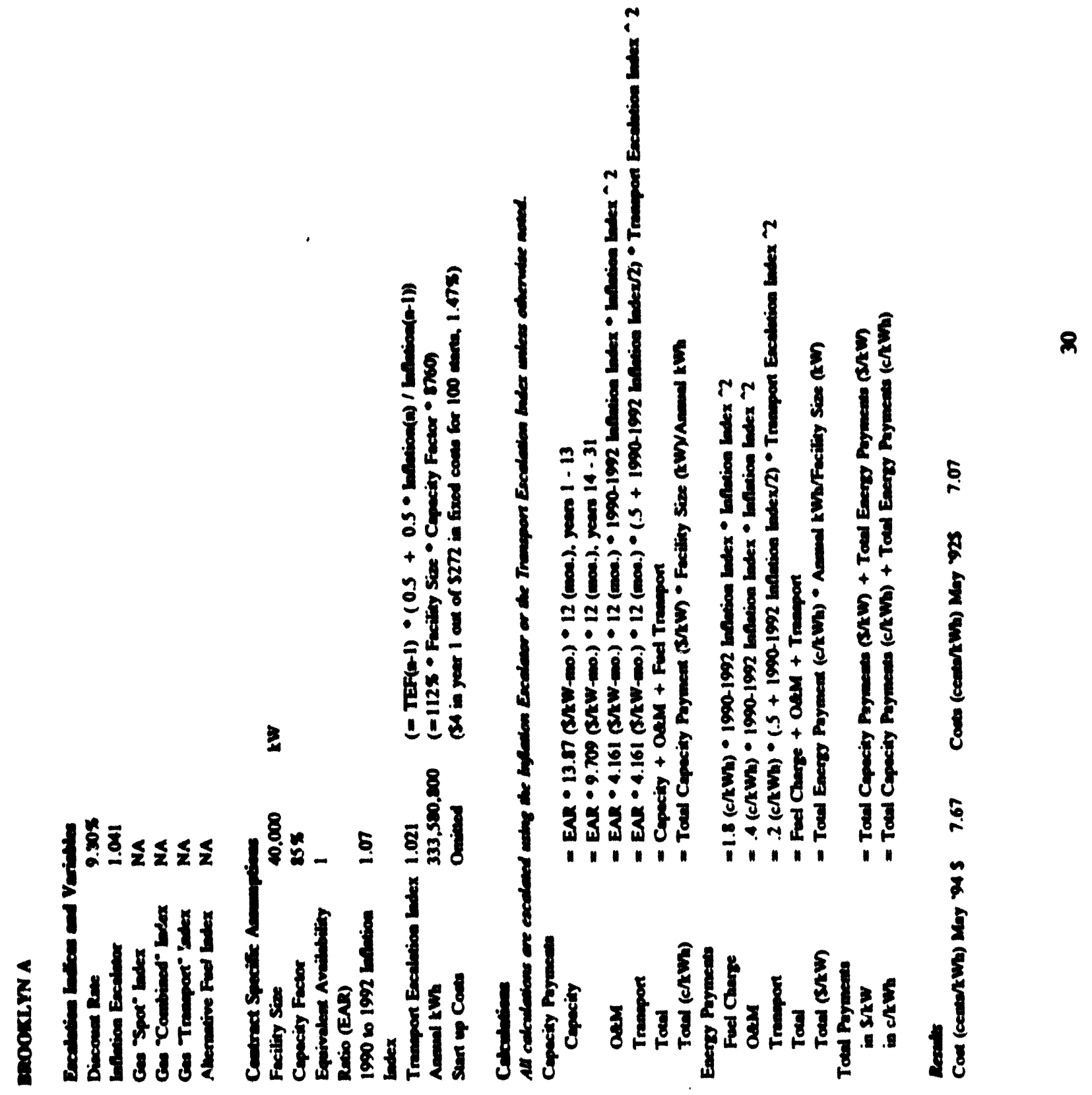




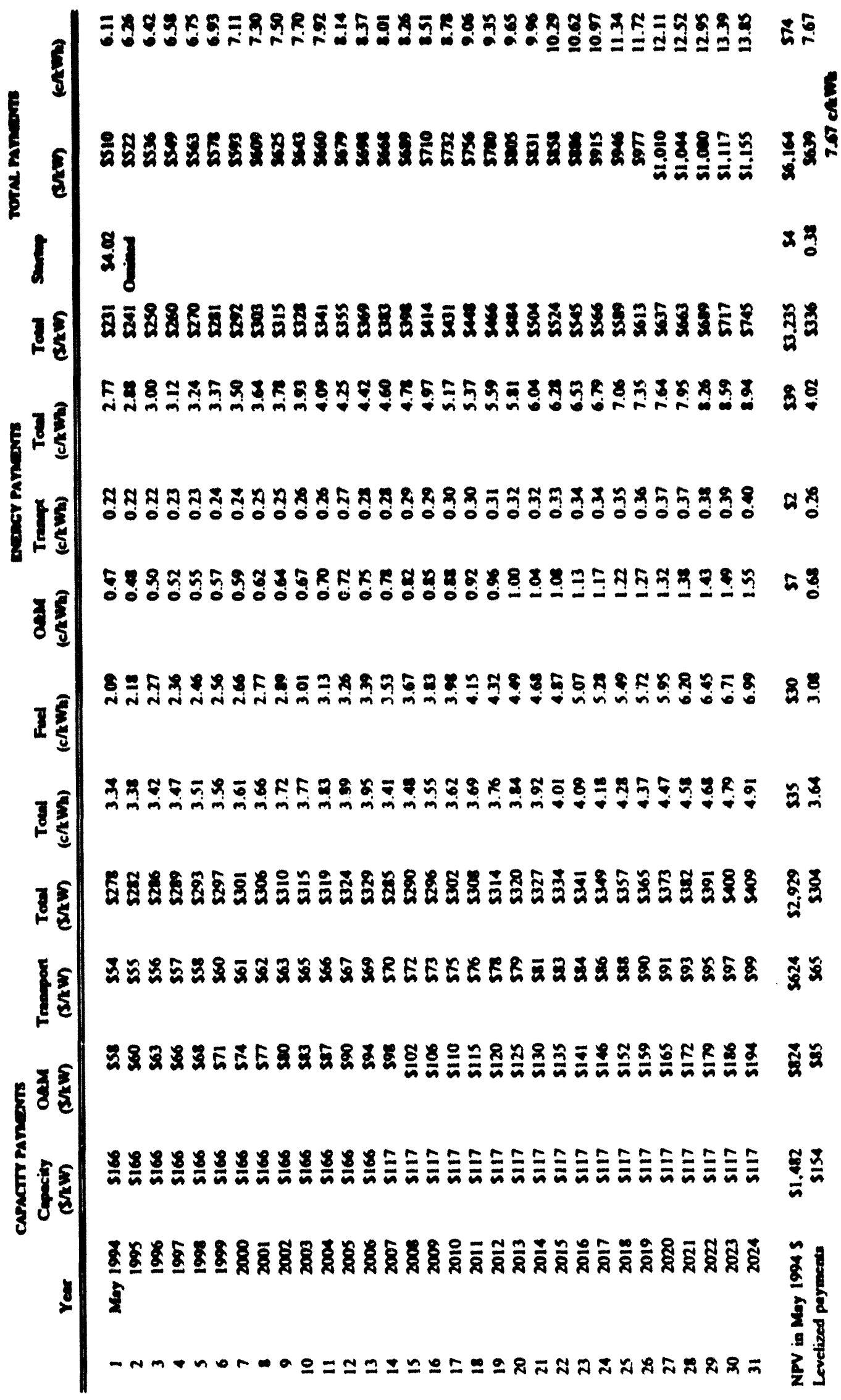




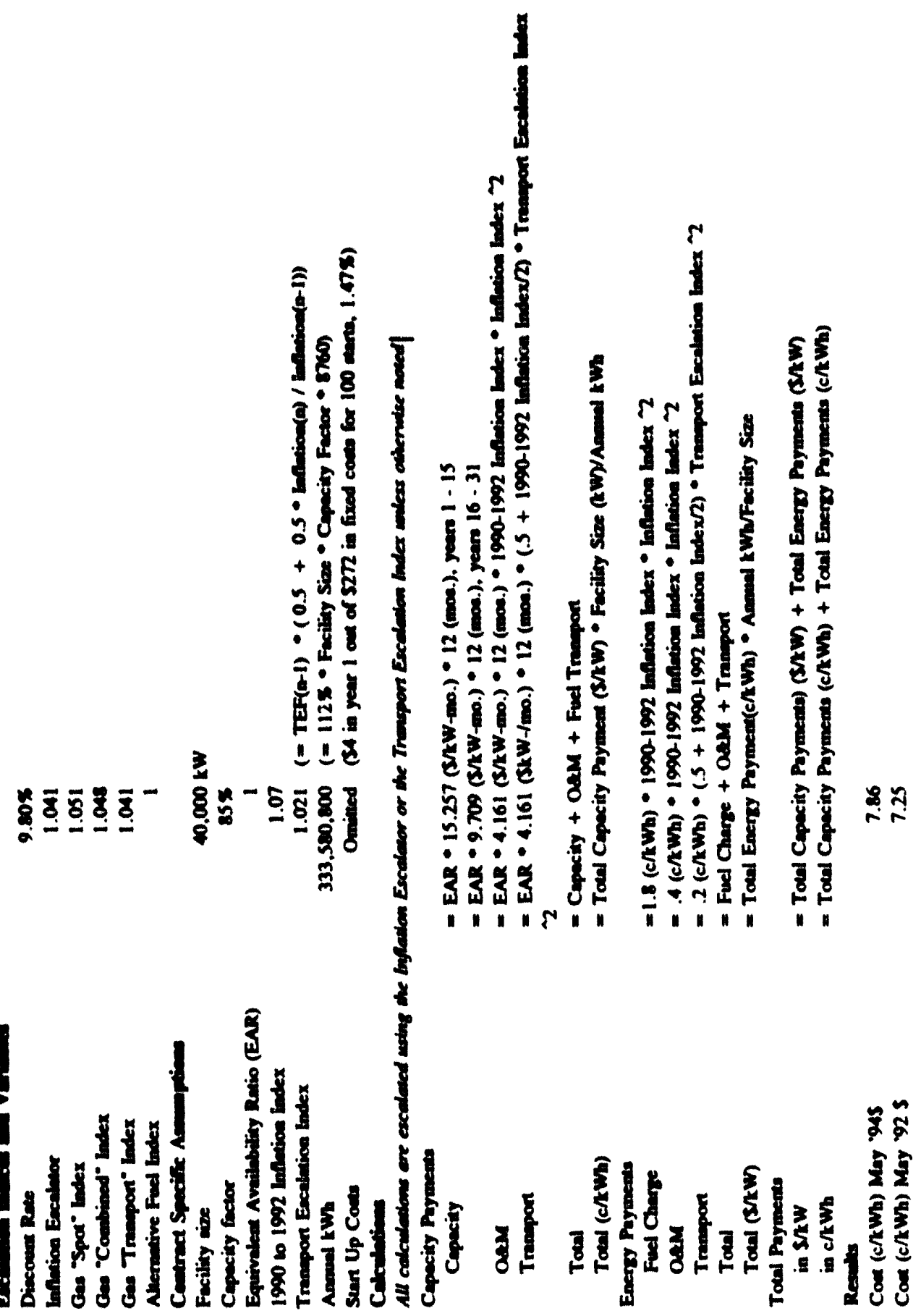




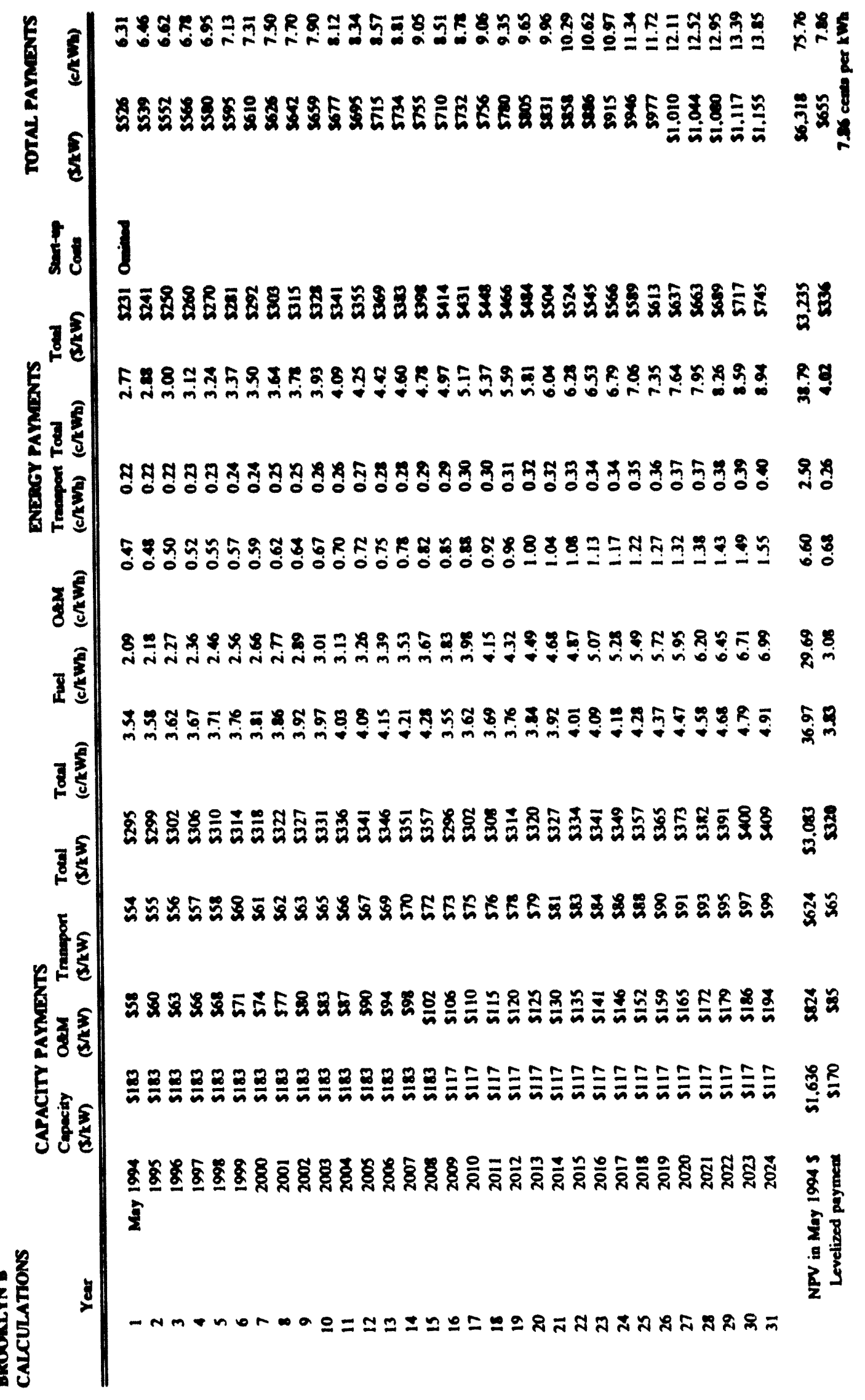




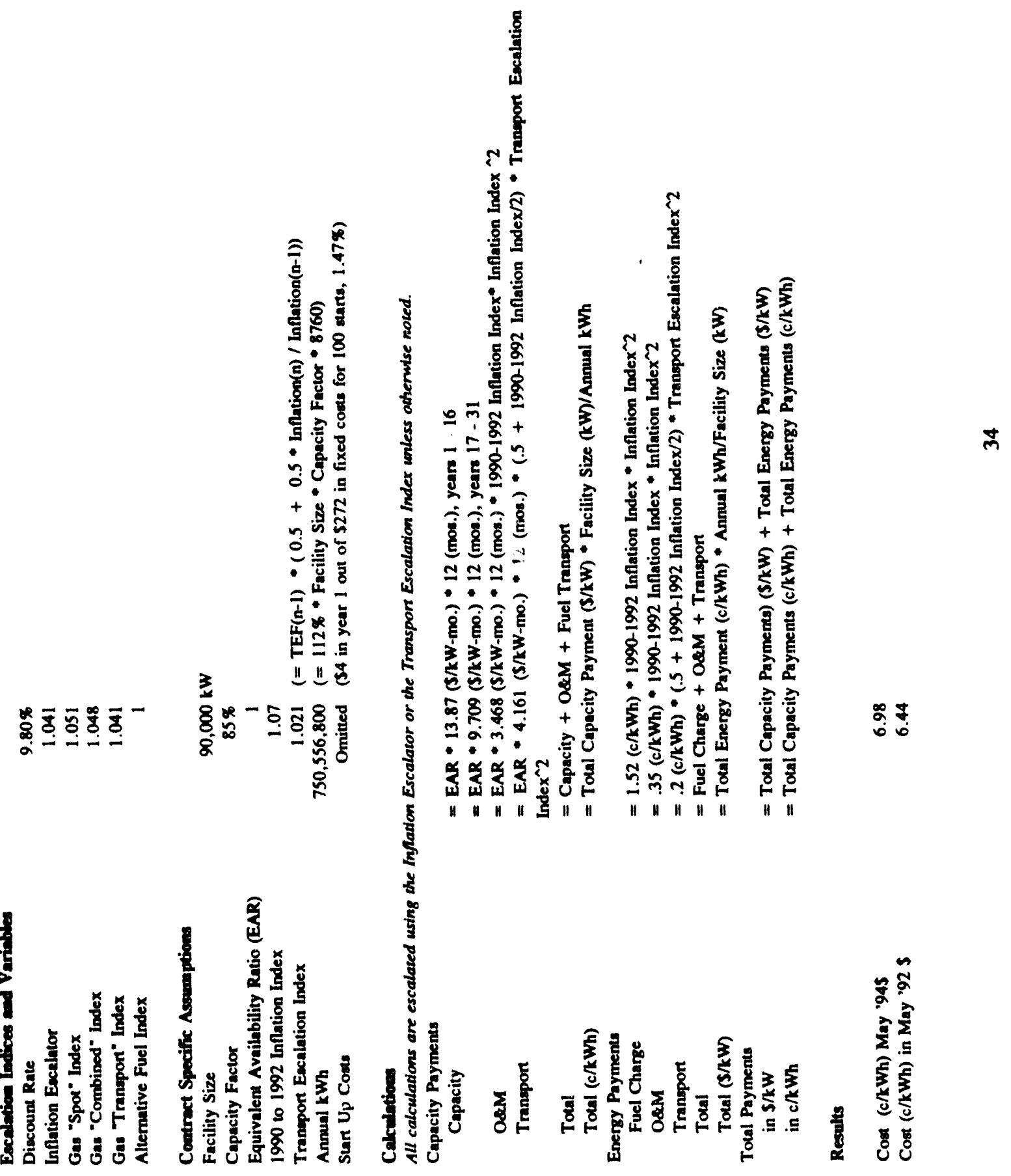




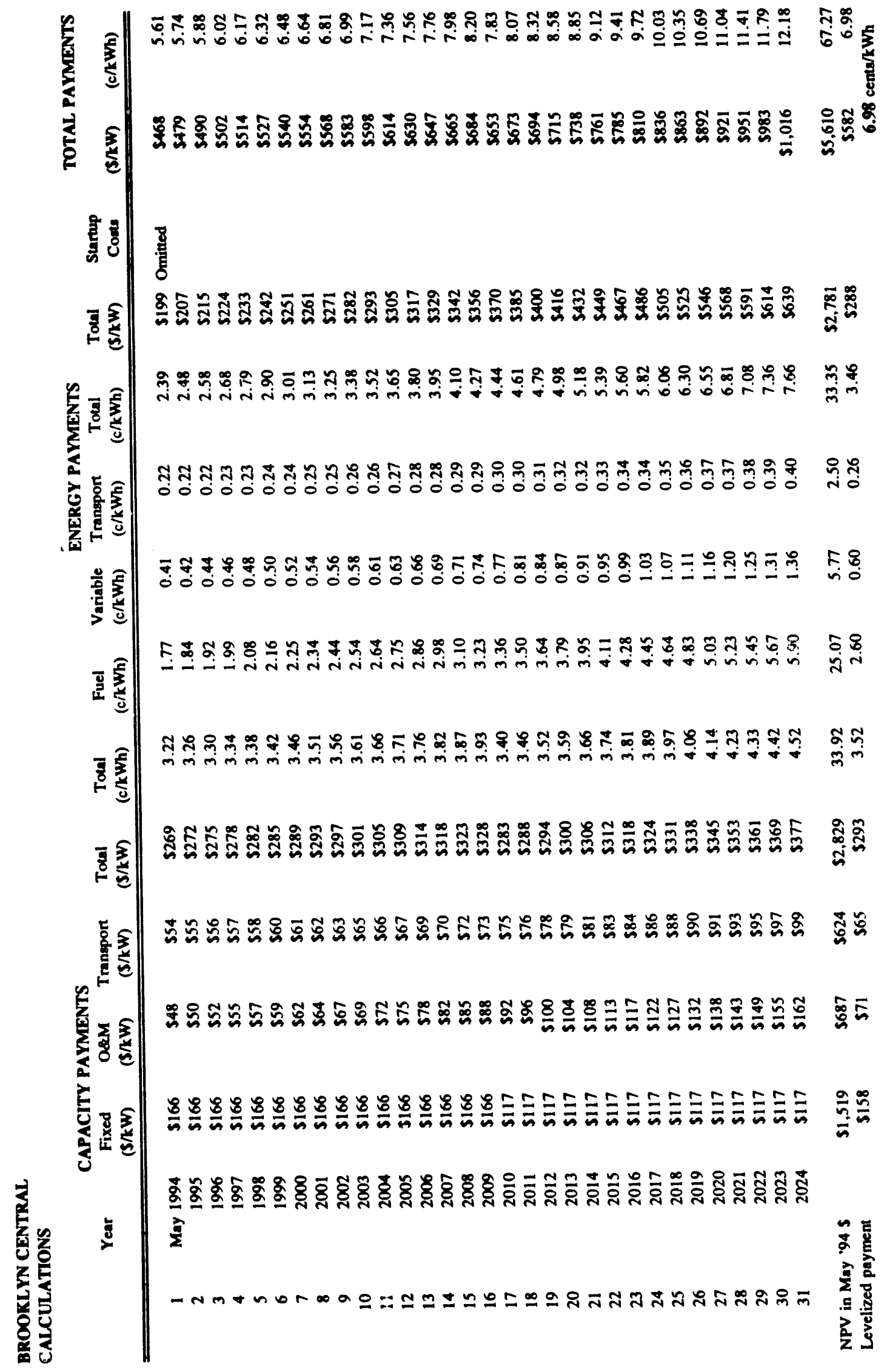



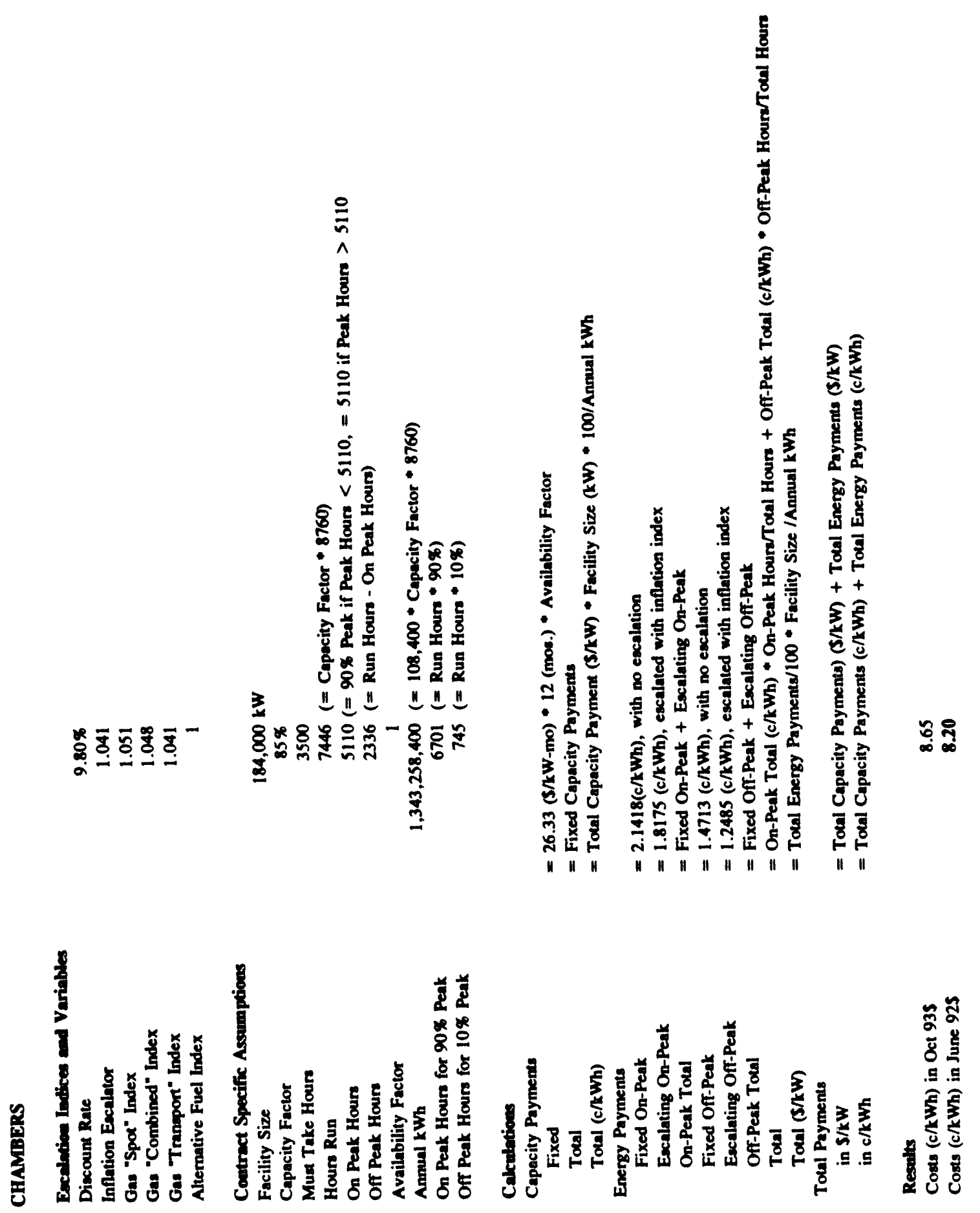


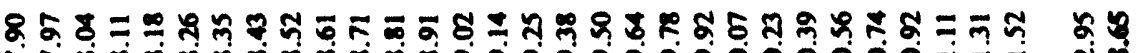

서

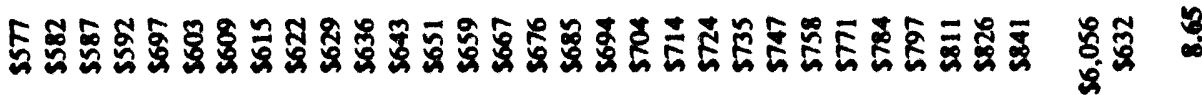

胥

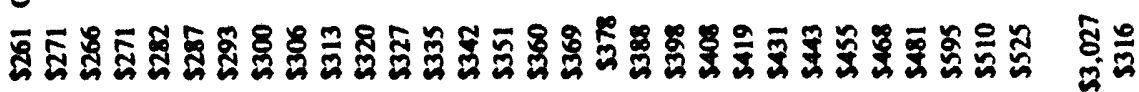

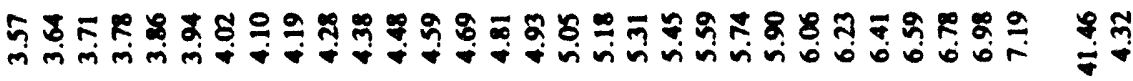

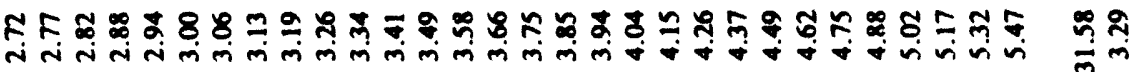

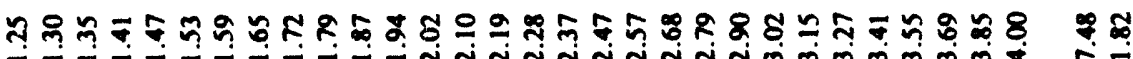

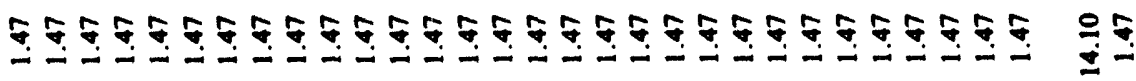

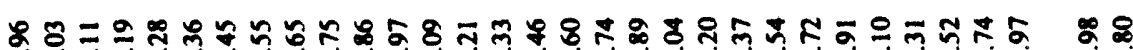

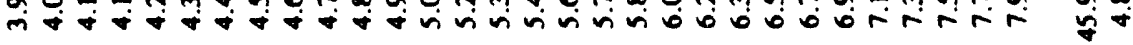

E

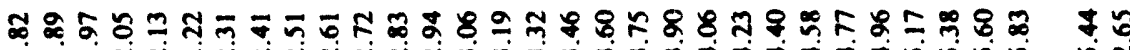

- i - i

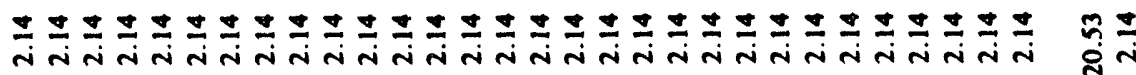

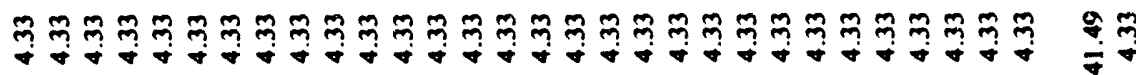

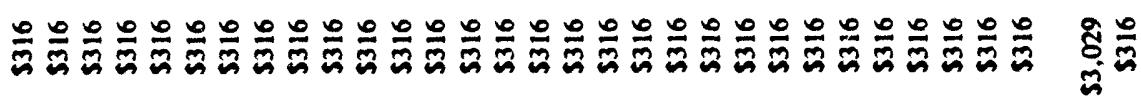

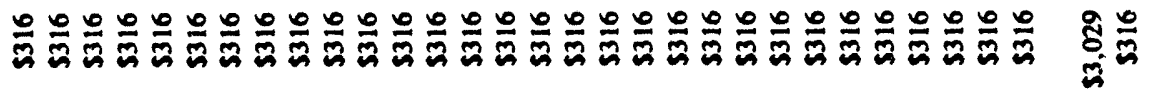

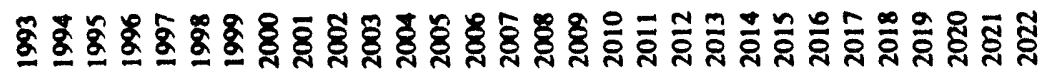
$\overline{8}$ 


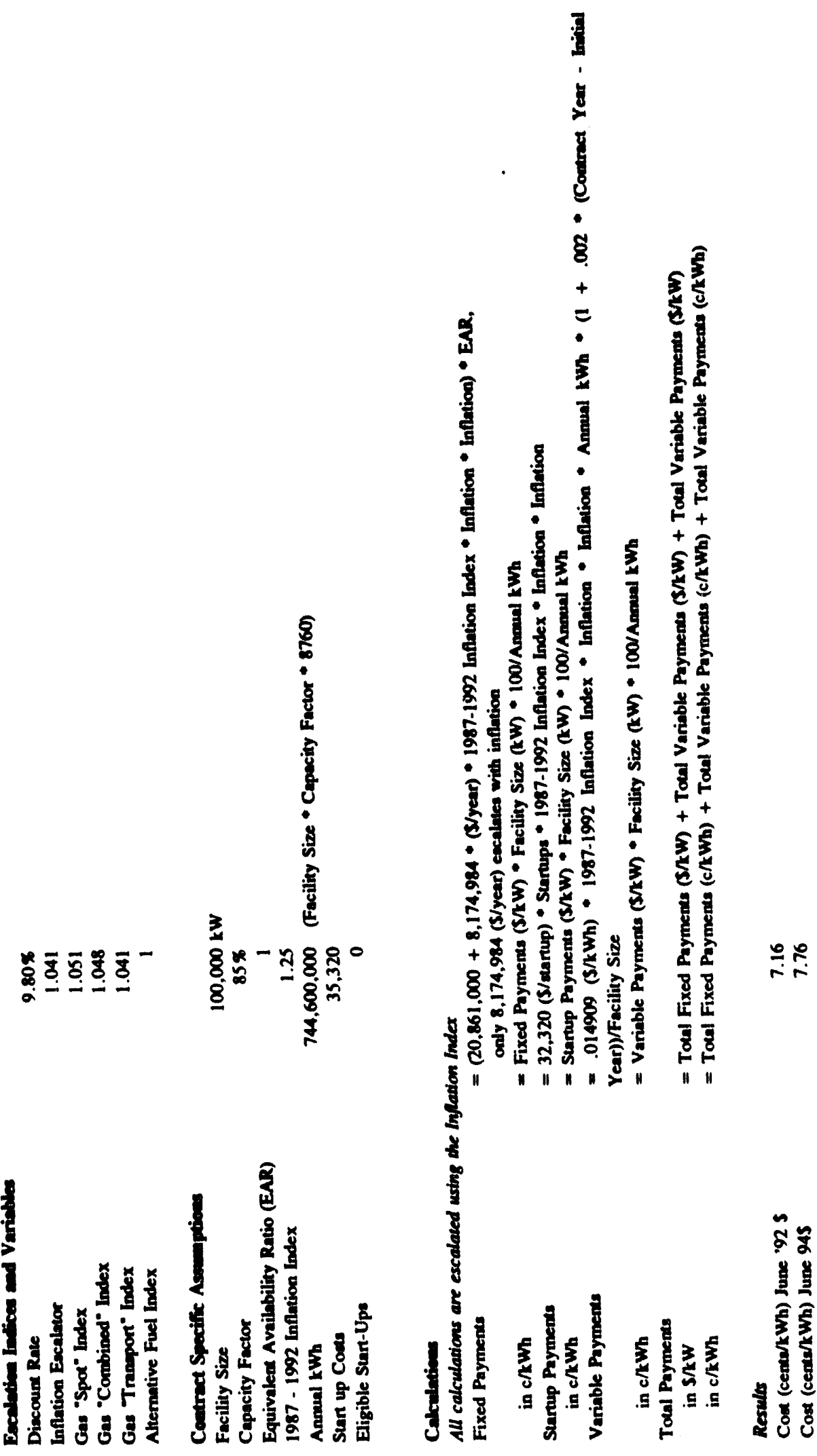




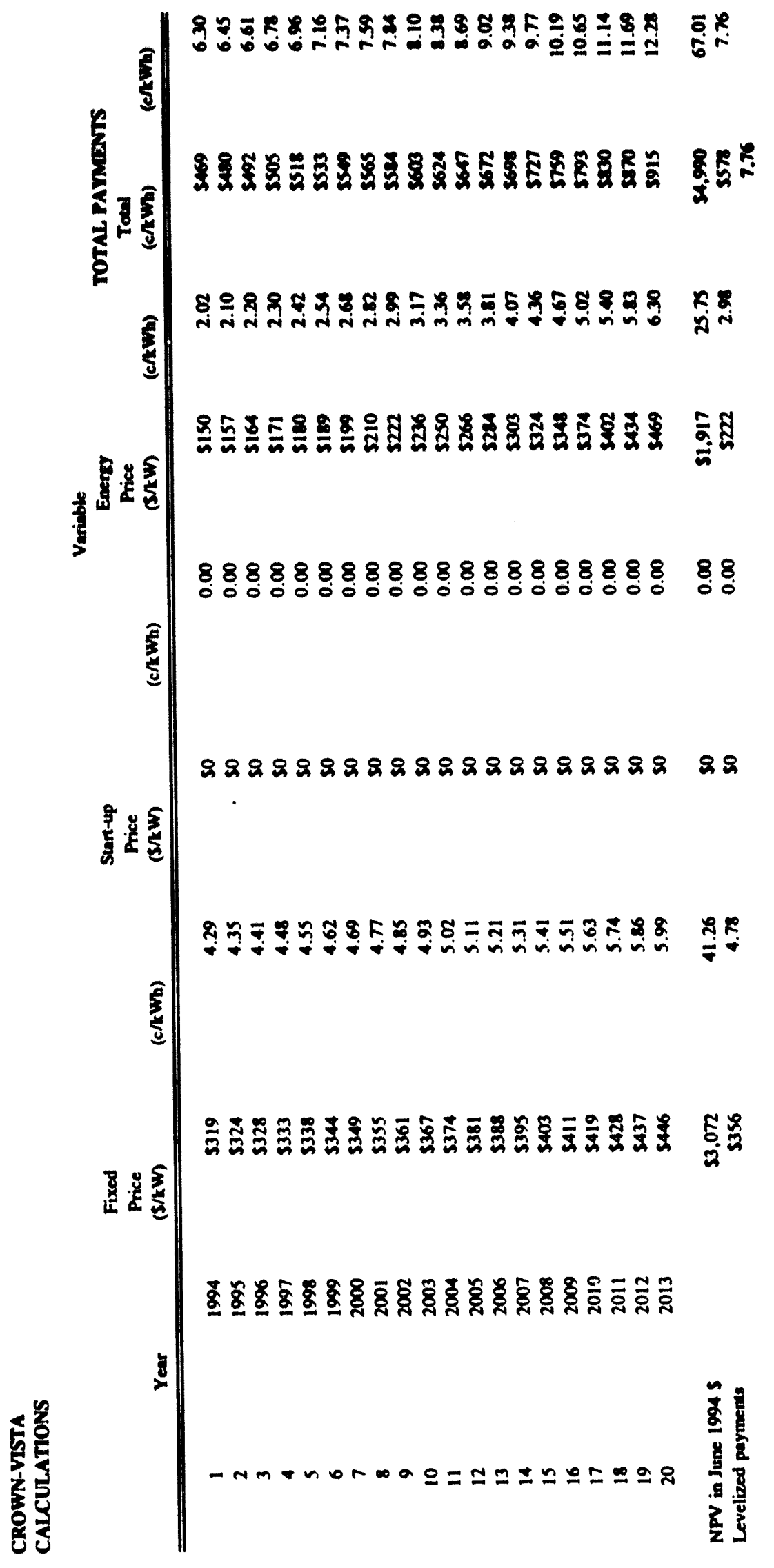




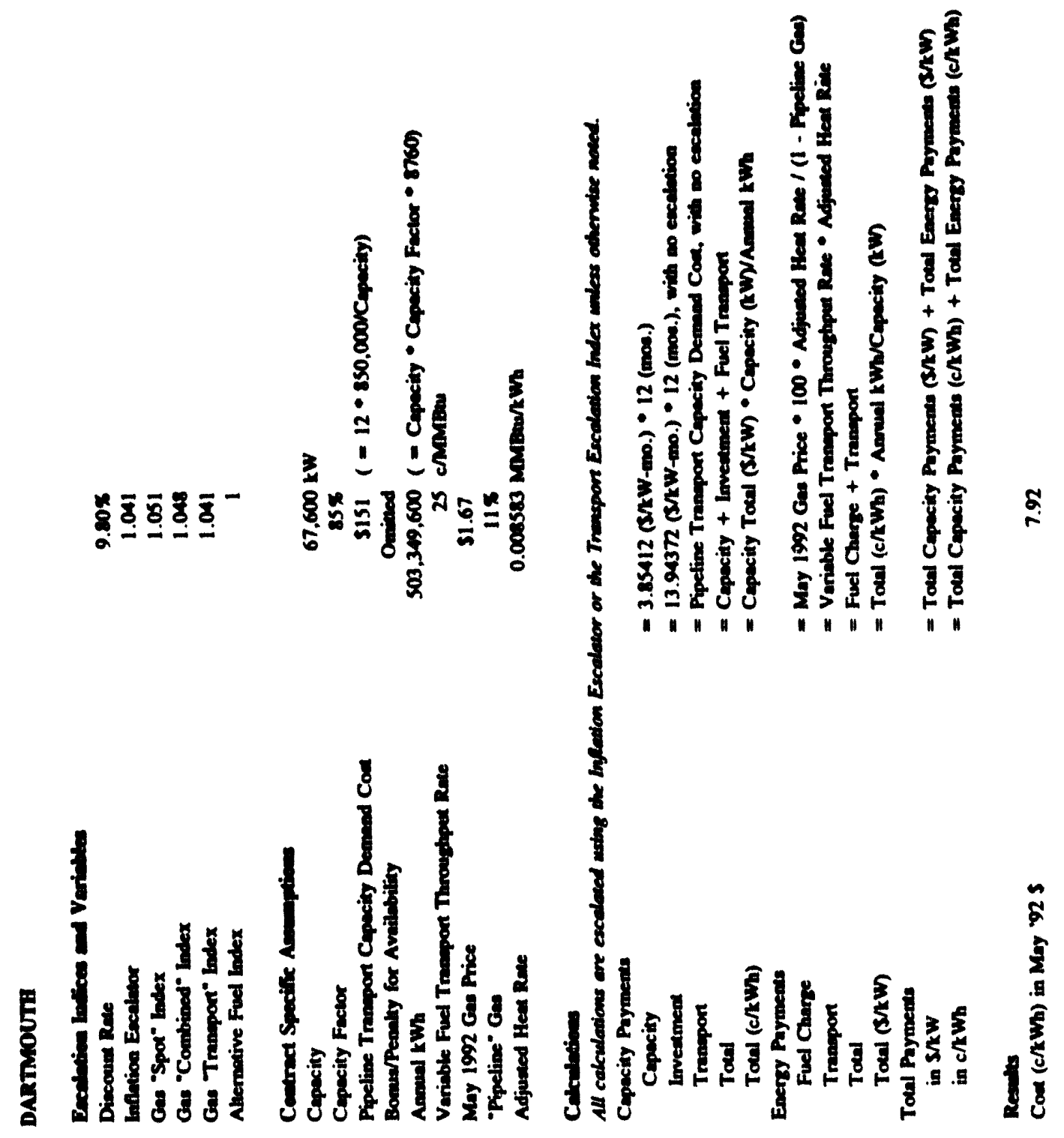




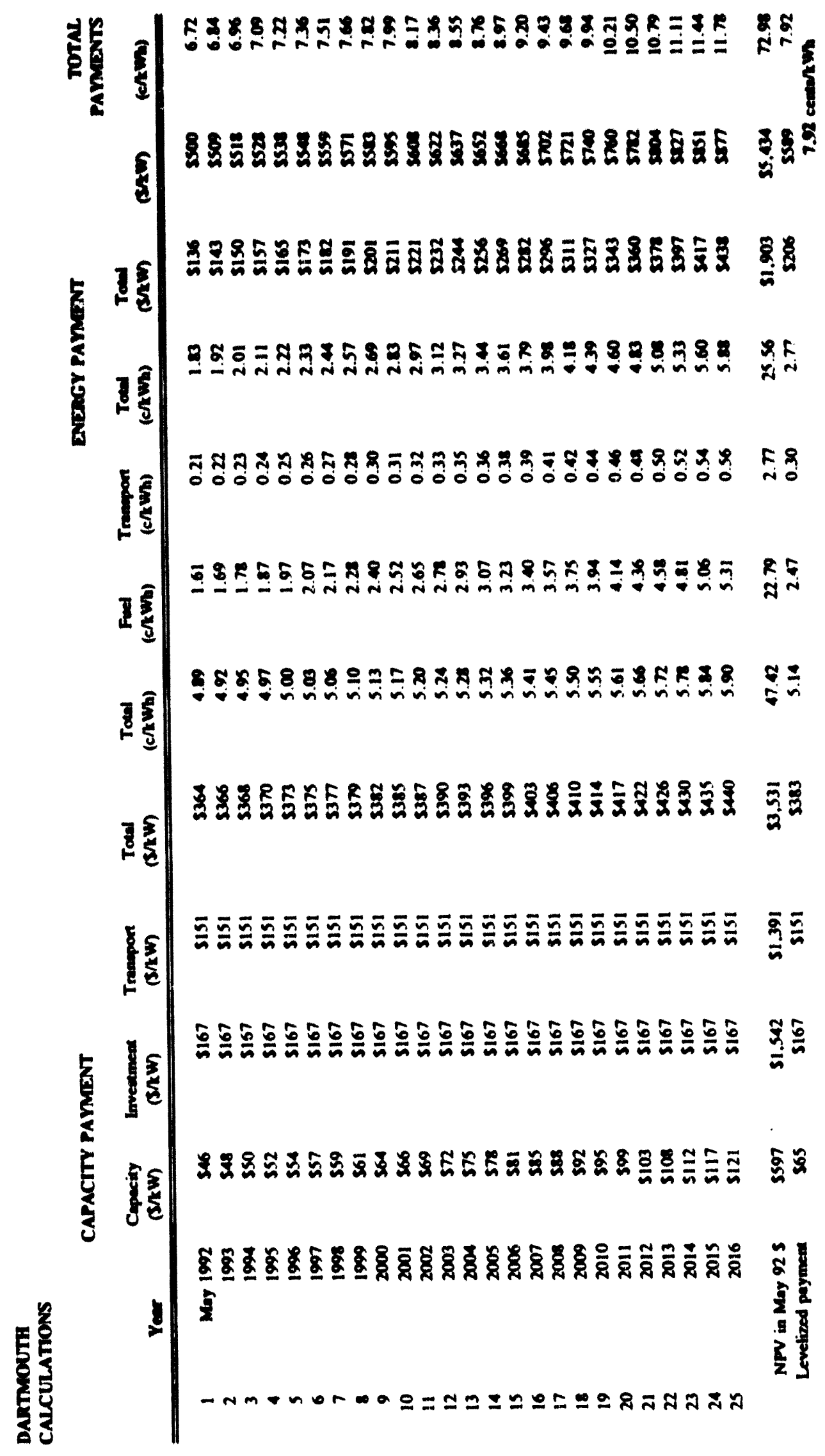



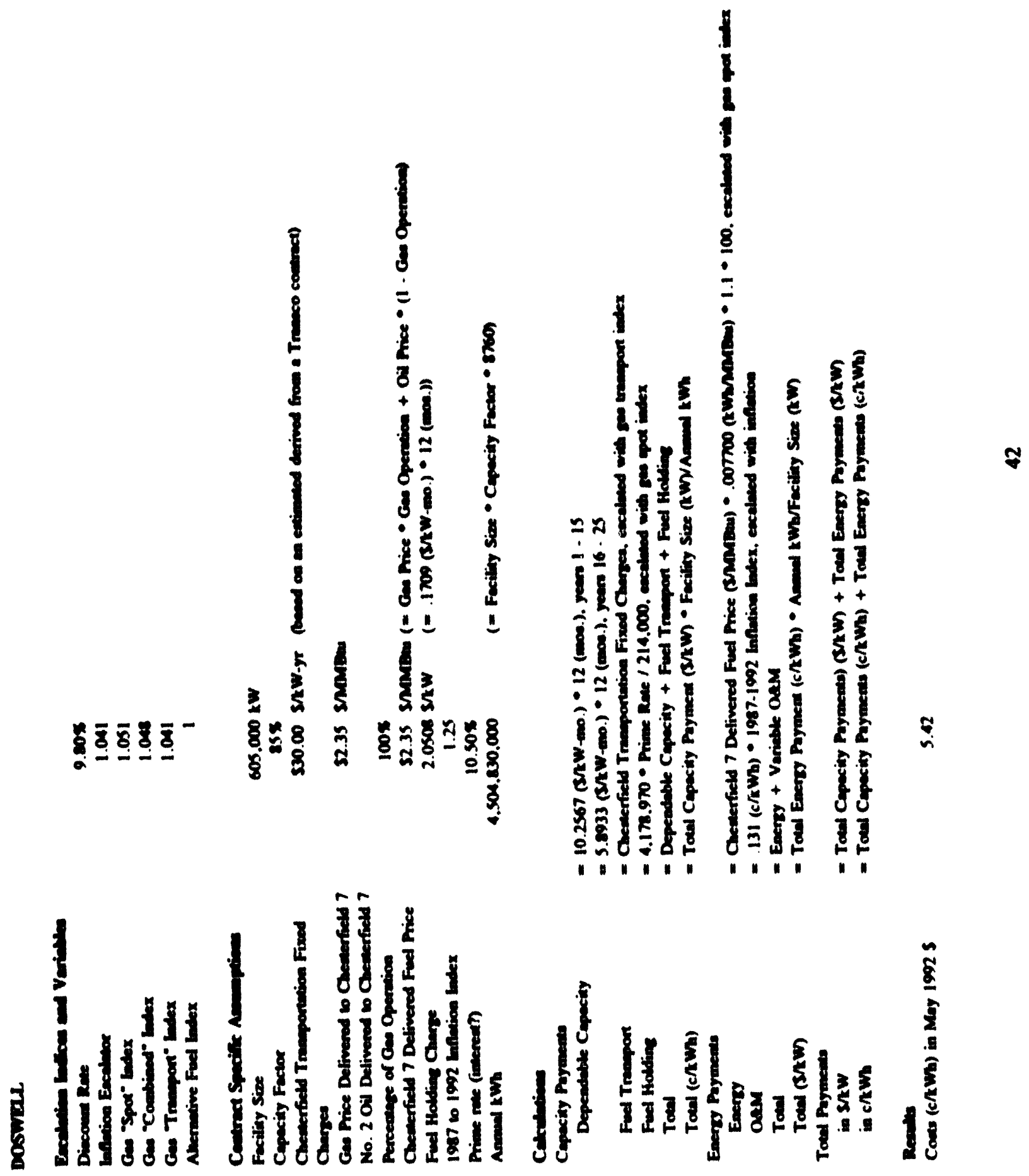


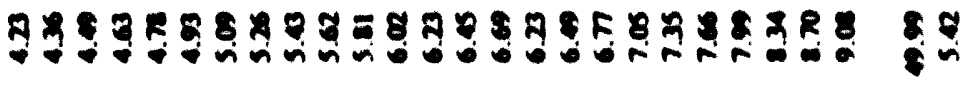

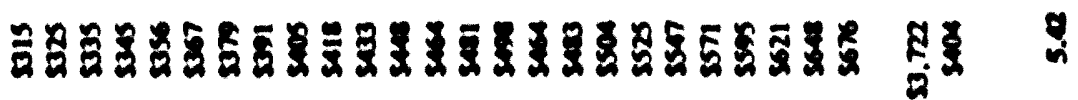

I

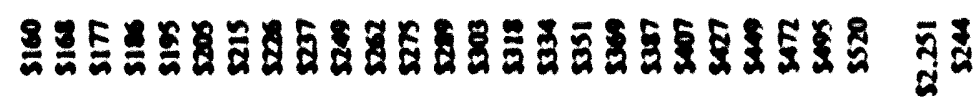

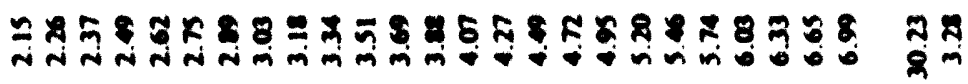

Is

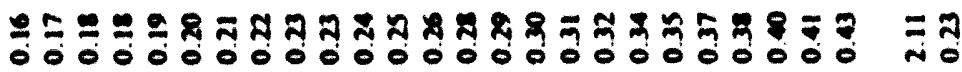

3.

\$s

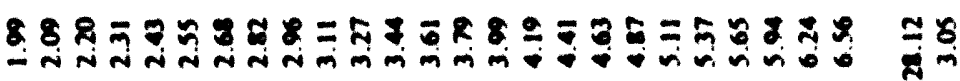

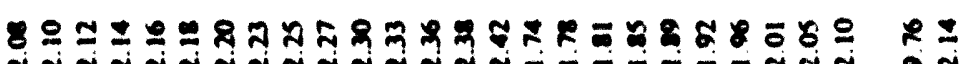
害

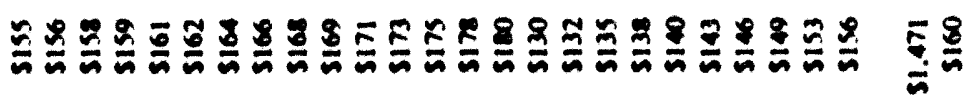

害急

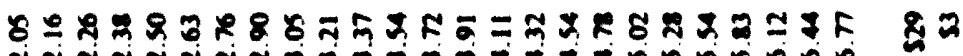

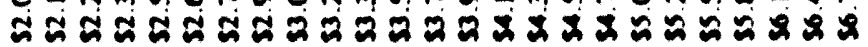

影密

II

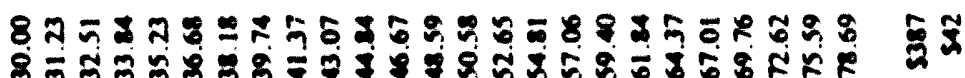

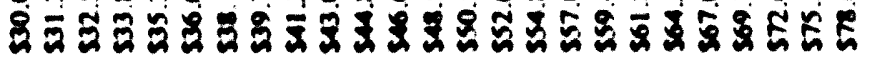

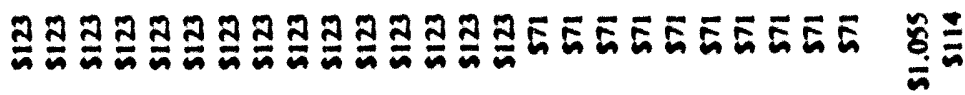

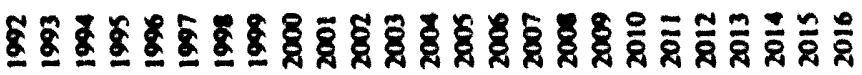




\section{Boltsvile:}

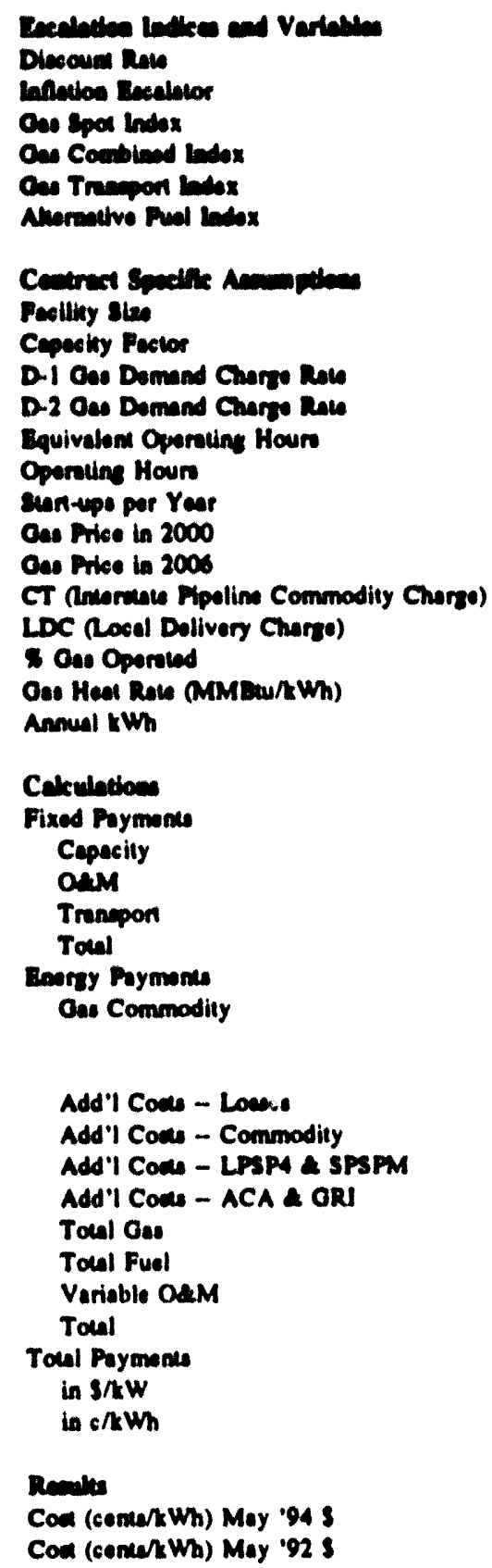

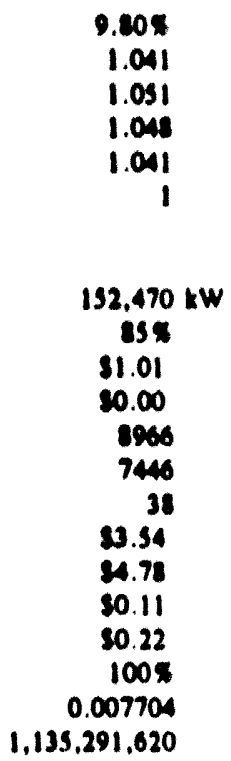

- Monthly paymente in coneracl (\$) 12 (moe.)/Facility size (kW)

- 436,250 (\$/mo.) * 12 (mos.)/Facility siza (EW), eccalated with innation

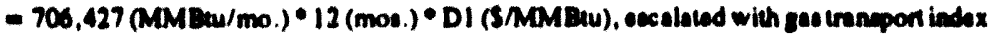

- Capacity + OeM + Fual Tronspon

- 3.53 (\$MMMBw), years 1.7

- Oas Price 2000 - Oes Spor Indox, eccalated with ges apot index, years 8 - 12

- One Price 20006, eccalaced with gas epot index, yearn 13 - 20

- Oan Commodity + 7.47\$/(1 - 7.47\%)

- CT + LDC, eccalated with gas tnnepon index

- 097 (BMMMBu), escalaled with gat tranepon index

- 022 (SMMMBiv), eccelaled with gas tronepor index

- Oes Commodily (SMMMBu) + Additional Cons (SMMMBau)

- Toul Oas (SMMMBtw) - Oas Heal RAle MMBru/tWh) - Opernting Houn

- 95 (SMour) - Equivalent Operating Hourn 12 (mos.)/Facility Size (RW

- Toul Fuel + Variable OSM

- Toul Fixed Payments (\$/kW) + Toul Variable Payments (\$/kW)

- Toul Fixed Paymens (c/nWh) + Toul Veriable Paymenus (c/kWh)
8.46

7.80 


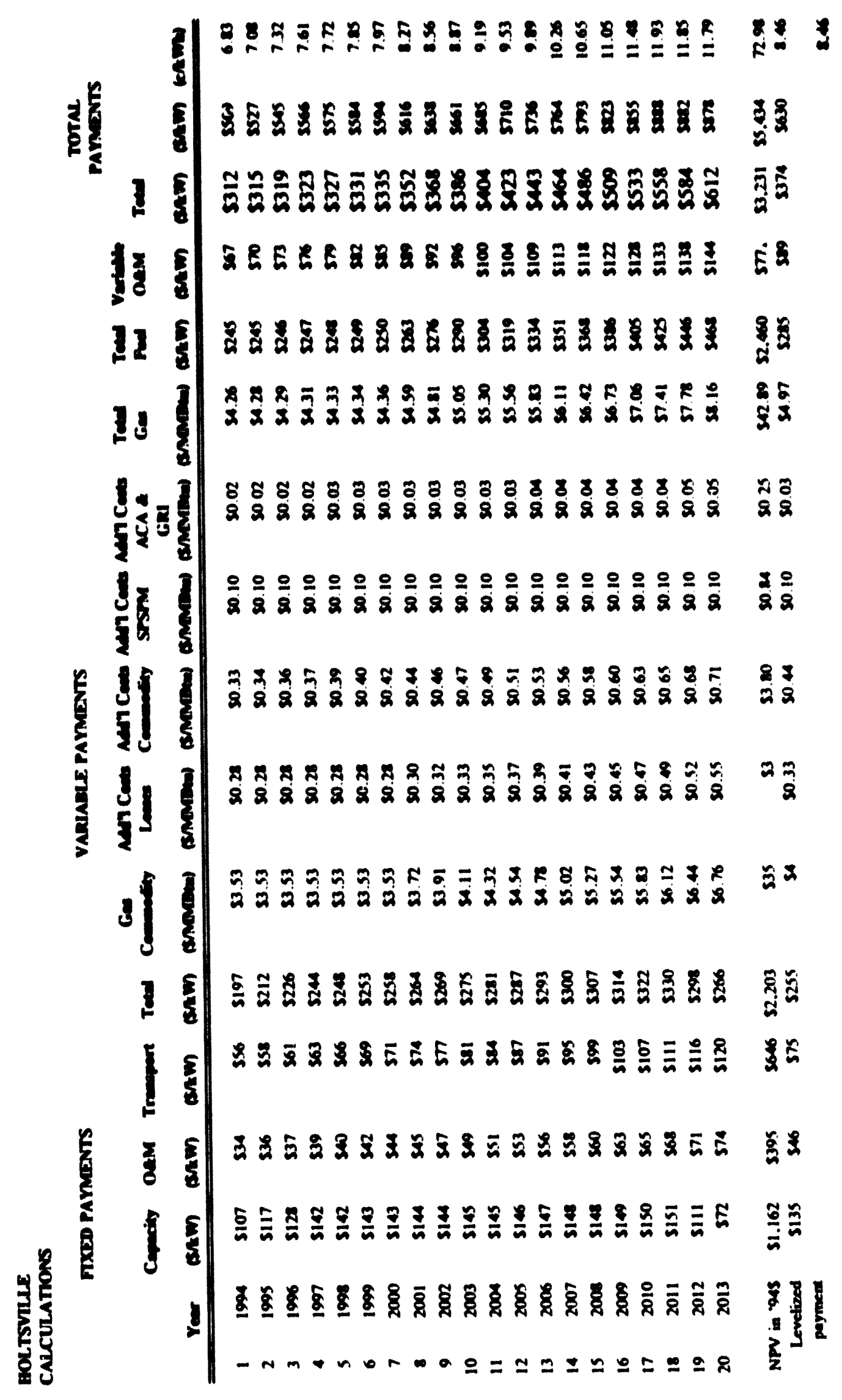




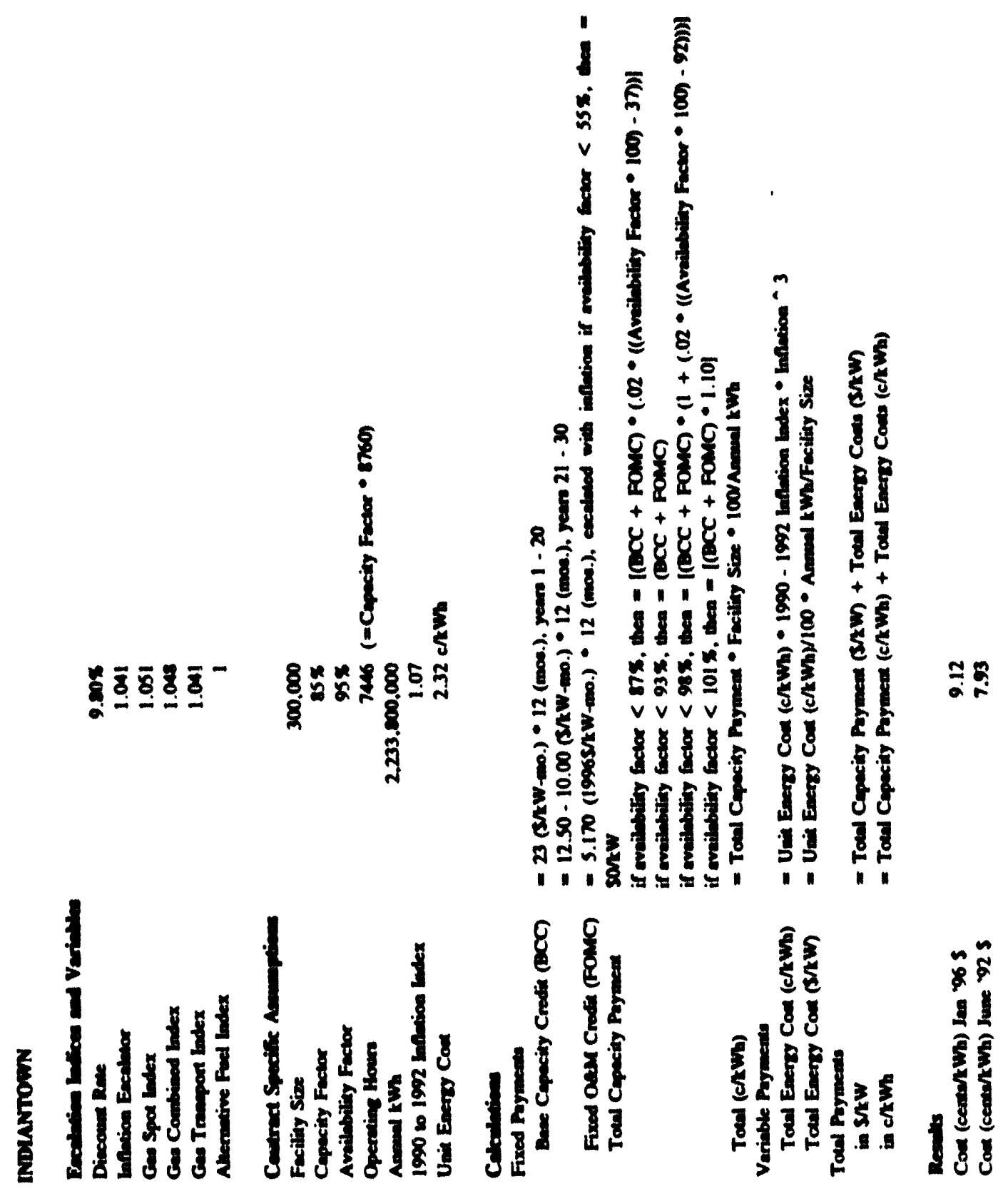




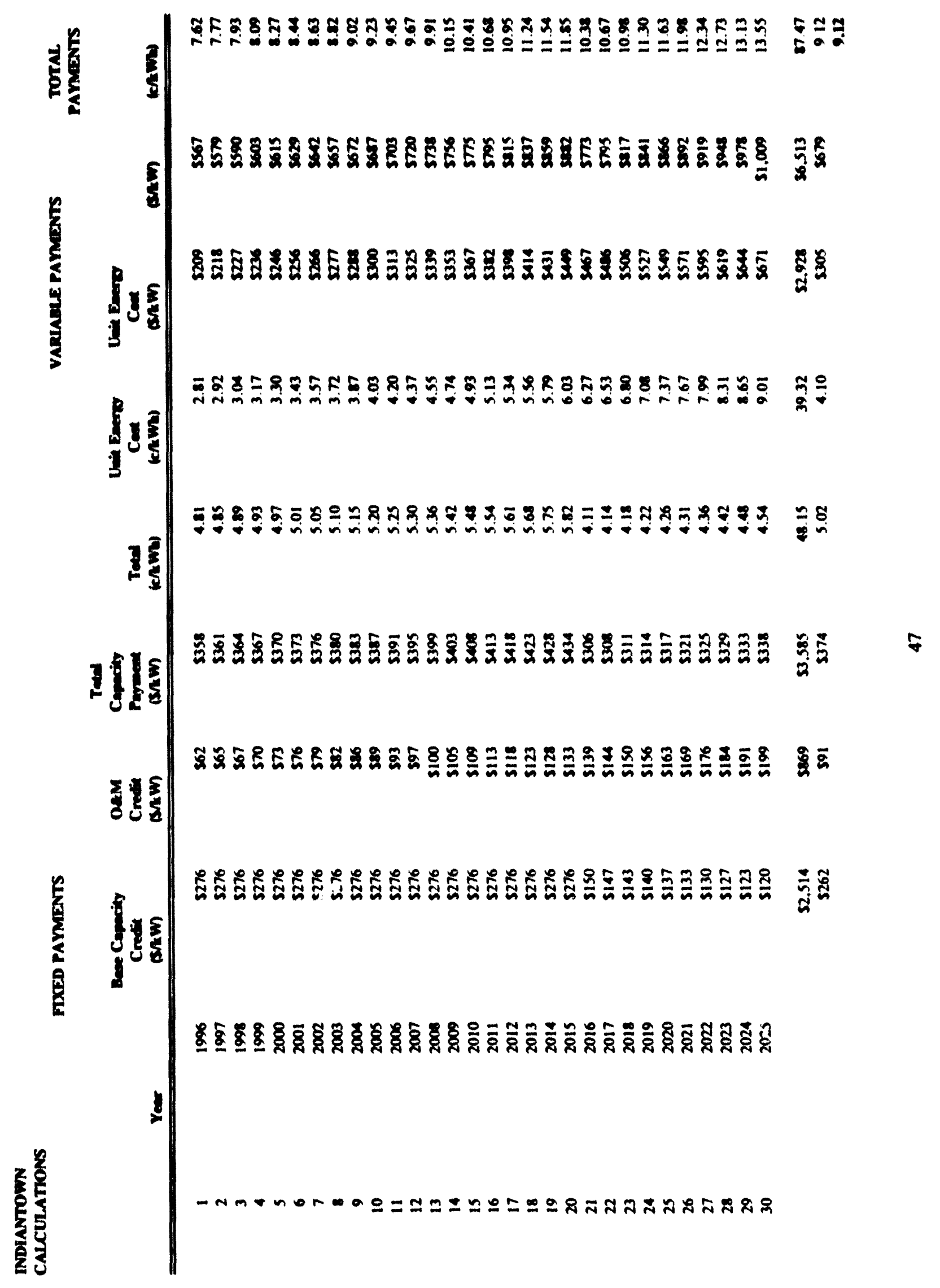



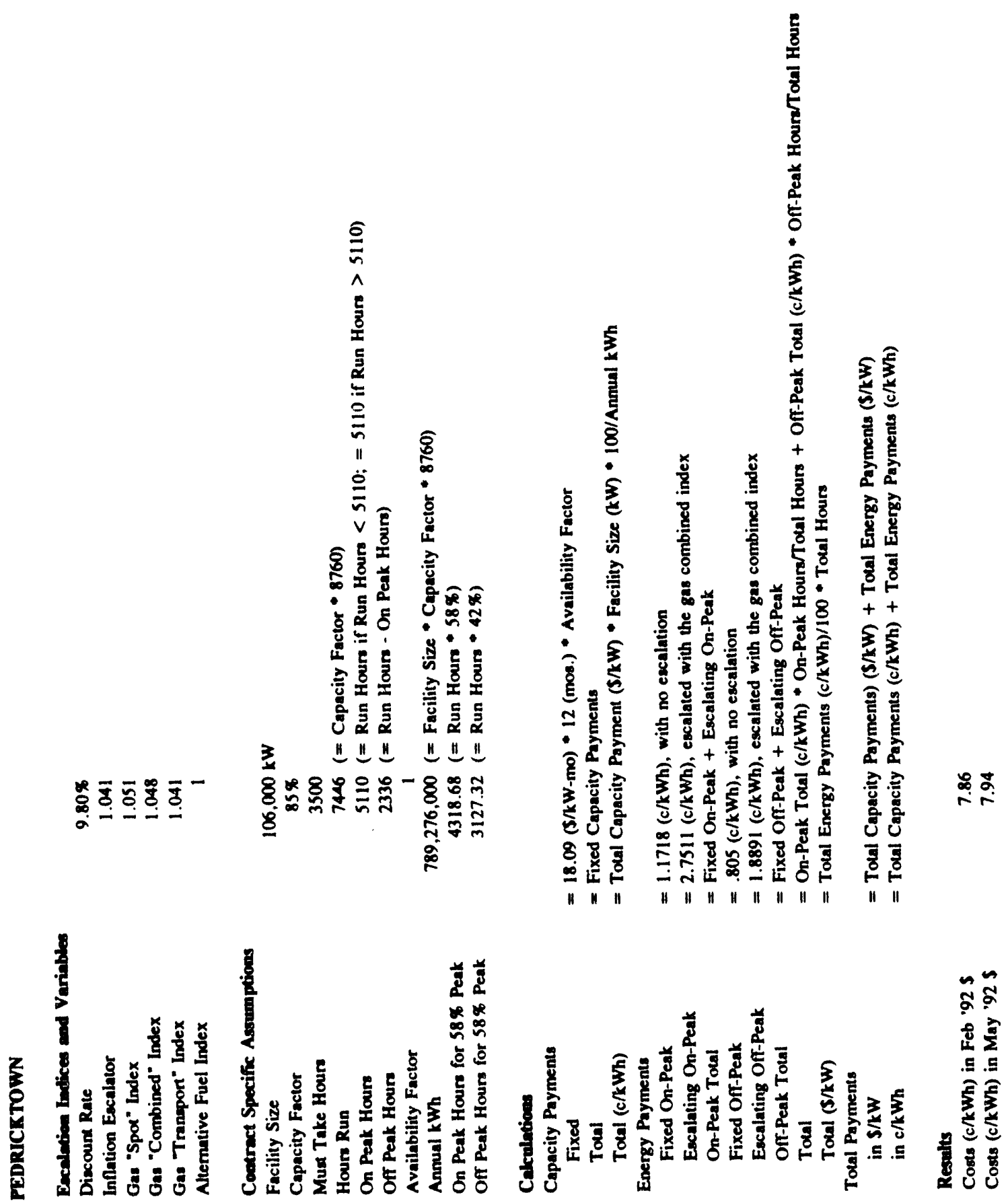


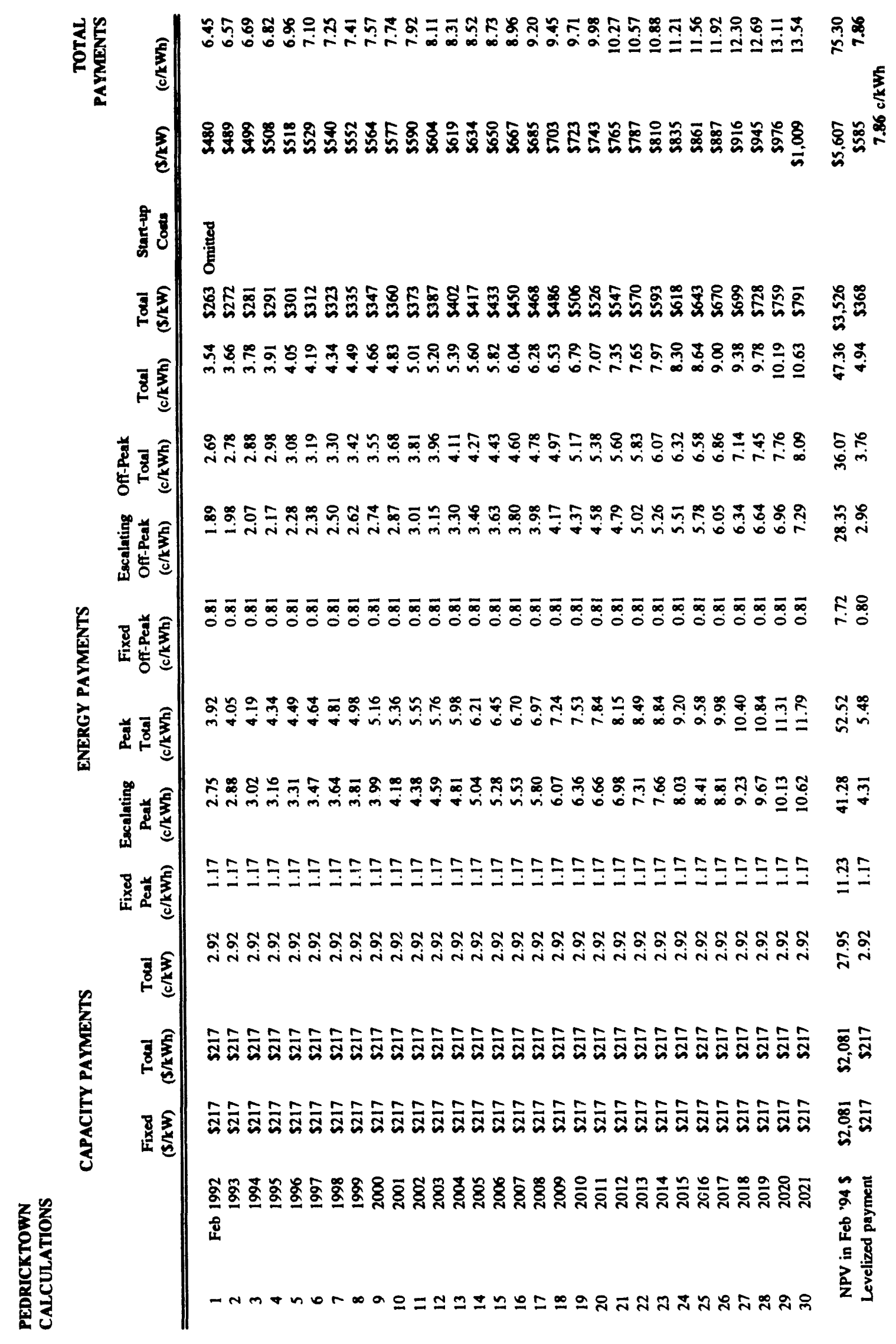




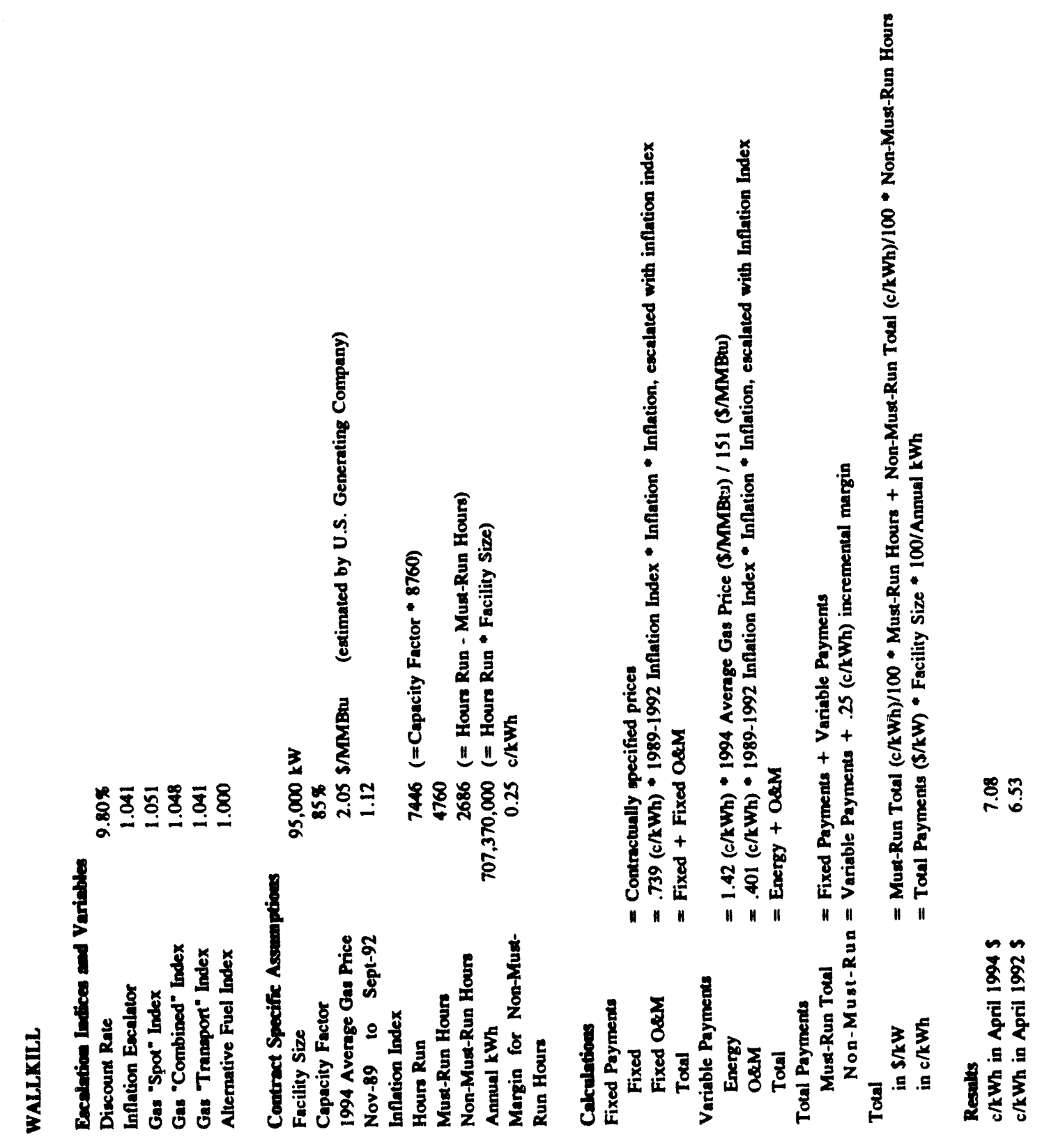




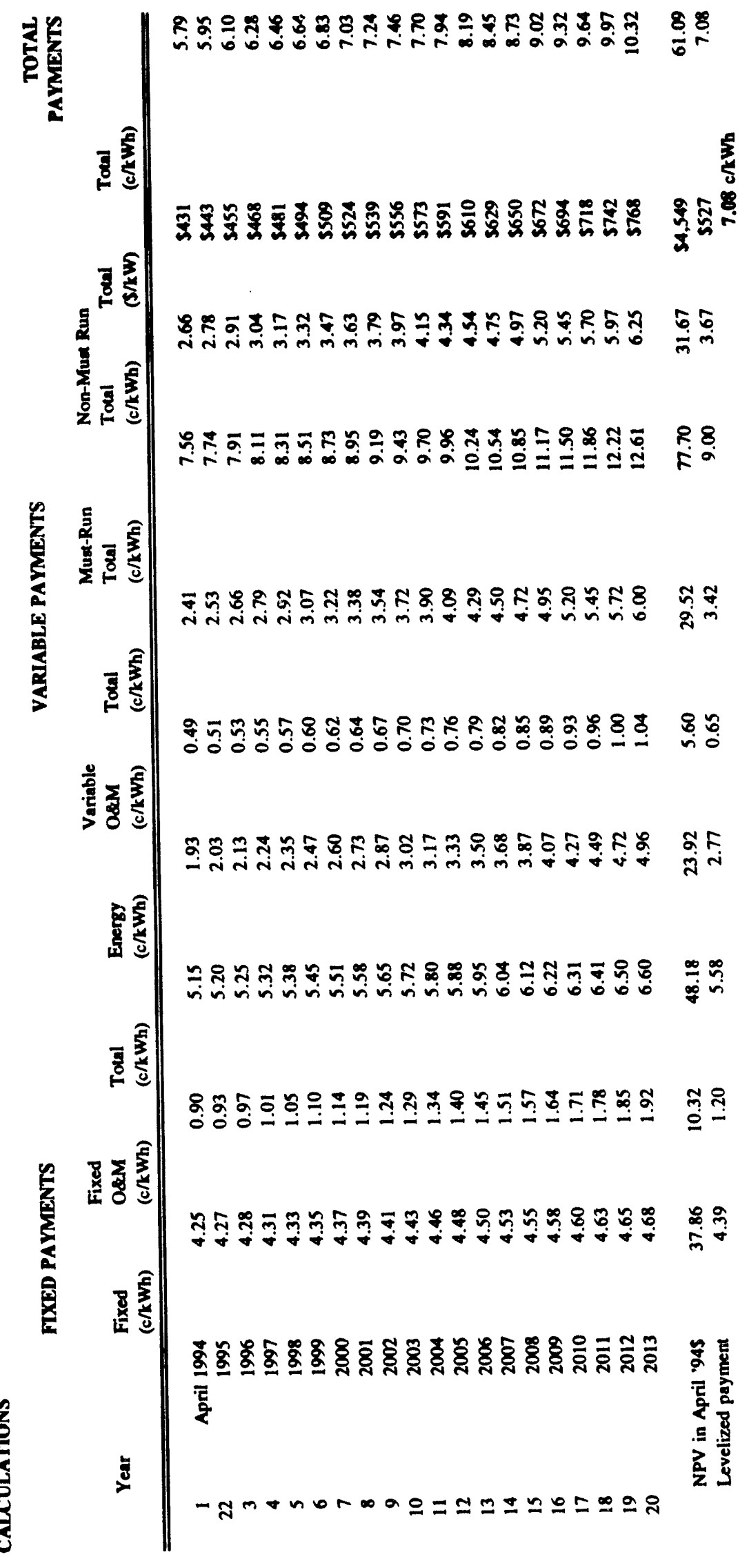



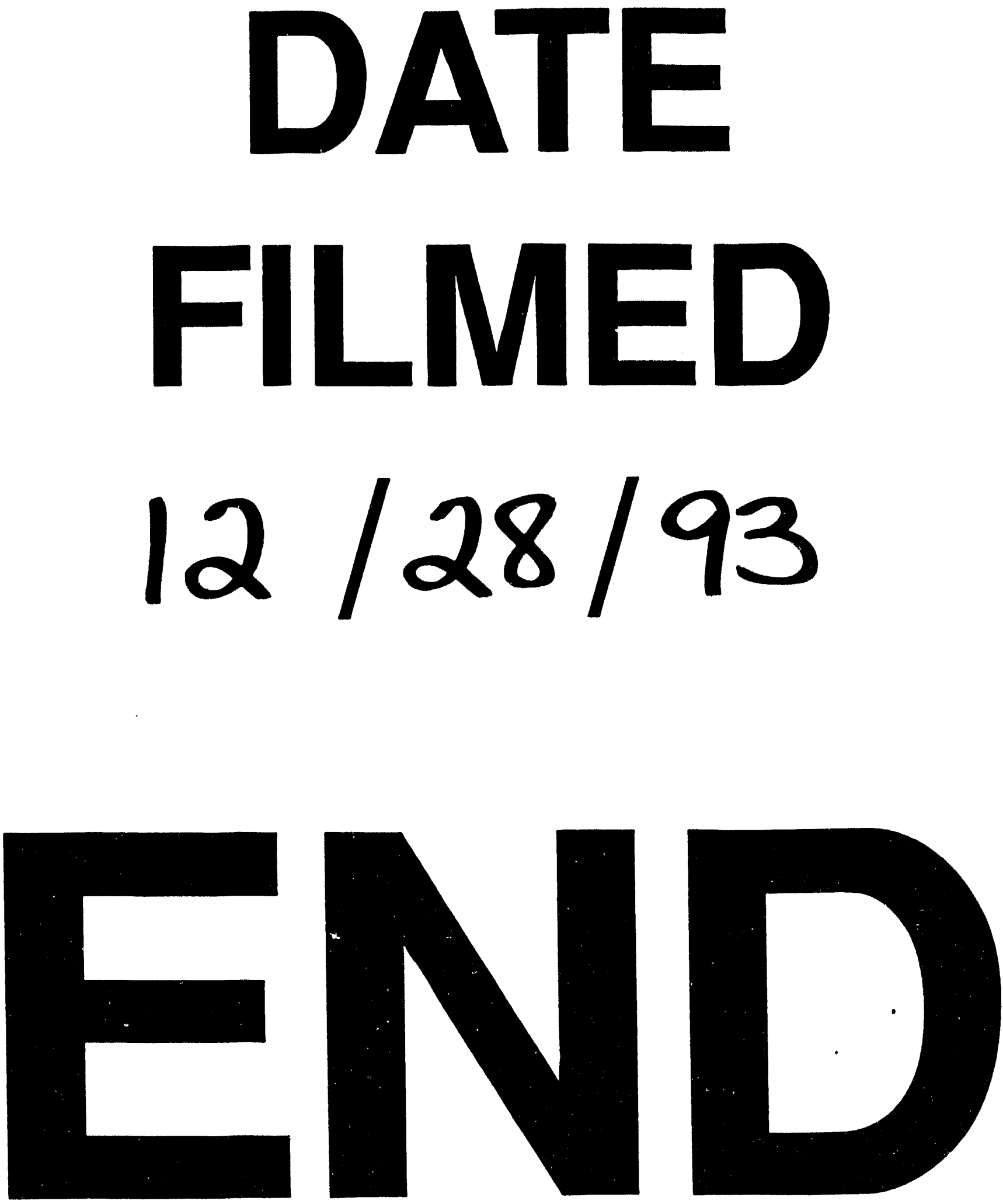
